\title{
L-Thyroxine Improves Vestibular Compensation in a Rat Model of Acute Peripheral Vestibulopathy: Cellular and Behavioral Aspects
}

\author{
Guillaume Rastoldo ${ }^{1}$, Emna Marouane ${ }^{1} \mathbb{D}$, Nada El-Mahmoudi ${ }^{1}$, David Péricat ${ }^{2}$, Isabelle Watabe ${ }^{1} \mathbb{D}$, \\ Agnes Lapotre ${ }^{1}$, Alain Tonetto ${ }^{3}$, Alejandra López-Juárez ${ }^{4}$, Abdessadek El-Ahmadi ${ }^{1}$, Philippe Caron ${ }^{5}$, \\ Marie-José Esteve Fraysse ${ }^{6}$, Christian Chabbert ${ }^{1,7}$, Andreas Zwergal ${ }^{8,9}$ and Brahim Tighilet ${ }^{1,7, * \text { (D) }}$
}

Citation: Rastoldo, G.; Marouane, E.; El-Mahmoudi, N.; Péricat, D.;

Watabe, I.; Lapotre, A.; Tonetto, A.; López-Juárez, A.; El-Ahmadi, A.; Caron, P.; et al. L-Thyroxine Improves Vestibular Compensation in a Rat Model of Acute Peripheral Vestibulopathy: Cellular and Behavioral Aspects. Cells 2022, 11, 684 https://doi.org/10.3390/cells11040684

Academic Editor: Luisa Alexandra Meireles Pinto

Received: 8 January 2022

Accepted: 10 February 2022

Published: 16 February 2022

Publisher's Note: MDPI stays neutral with regard to jurisdictional claims in published maps and institutional affiliations.

Copyright: (C) 2022 by the authors. Licensee MDPI, Basel, Switzerland. This article is an open access article distributed under the terms and conditions of the Creative Commons Attribution (CC BY) license (https:// creativecommons.org/licenses/by/ $4.0 /)$.
1 Aix Marseille Université-CNRS, Laboratoire de Neurosciences Cognitives, LNC UMR 7291, 13331 Marseille, France; guillaume.rastoldo@univ-amu.fr (G.R.); emna.marouane@gmail.com (E.M.); nada.el-mahmoudi@univ-amu.fr (N.E.-M.); isabelle.watabe@univ-amu.fr (I.W.); agnes.lapotre@univ-amu.fr (A.L.); abdessadek.el-ahmadi@univ-amu.fr (A.E.-A.); christian.chabbert@univ-amu.fr (C.C.)

2 Institute of Pharmacology and Structural Biology (IPBS), University of Toulouse, CNRS, 31400 Toulouse, France; david.pericat@ipbs.fr

3 Centrale Marseille, Aix Marseille Université-CNRS, FSCM (FR1739), PRATIM, 13331 Marseille, France; alain.tonetto@univ-amu.fr

4 Department of Chemical, Electronic and Biomedical Engineering, Division of Sciences and Engineering, University of Guanajuato, Guanajuato 38116, Mexico; lopez.sa@ugto.mx

5 Service d'Endocrinologie et Maladies Métaboliques, Pôle Cardio-Vasculaire et Métabolique, CHU de Rangueil-Larrey, 31059 Toulouse, France; caron.philippe.j@orange.fr

6 Service d'Oto-Rhino-Laryngologie, d'Oto-Neurologie et d'ORL Pédiatrique, Centre Hospitalier Universitaire de Toulouse, 31400 Toulouse, France; fraysse.mj@chu-toulouse.fr

7 GDR Physiopathologie Vestibulaire-Unité GDR2074, CNRS, 13003 Marseille, France

8 Department of Neurology, University Hospital, LMU Munich, 80539 Munich, Germany; andreas.zwergal@med.uni-muenchen.de

9 German Center for Vertigo and Balance Disorders, DSGZ, LMU Munich, 80539 Munich, Germany

* Correspondence: brahim.tighilet@univ-amu.fr; Tel.: +33-413550881; Fax: +33-413550869

\begin{abstract}
Unilateral vestibular lesions induce a vestibular syndrome, which recovers over time due to vestibular compensation. The therapeutic effect of L-Thyroxine (L-T4) on vestibular compensation was investigated by behavioral testing and immunohistochemical analysis in a rat model of unilateral vestibular neurectomy (UVN). We demonstrated that a short-term L-T4 treatment reduced the vestibular syndrome and significantly promoted vestibular compensation. Thyroid hormone receptors (TR $\alpha$ and TR $\beta$ ) and type II iodothyronine deiodinase (DIO2) were present in the vestibular nuclei (VN), supporting a local action of L-T4. We confirmed the T4-induced metabolic effects by demonstrating an increase in the number of cytochrome oxidase-labeled neurons in the VN three days after the lesion. L-T4 treatment modulated glial reaction by decreasing both microglia and oligodendrocytes in the deafferented VN three days after UVN and increased cell proliferation. Survival of newly generated cells in the deafferented vestibular nuclei was not affected, but microglial rather than neuronal differentiation was favored by L-T4 treatment.
\end{abstract}

Keywords: vestibular compensation; thyroid hormones; vertigo pharmacology; neurogenesis; microglial reaction; brain metabolism; vestibular nuclei

\section{Introduction}

A unilateral vestibular lesion induces in most species, including humans, a characteristic vestibular syndrome composed of oculomotor, posturo-locomotor, and perceptivecognitive deficits. These symptoms recover over days to weeks due to a well-known phenomenon called vestibular compensation. In neuroscience, this functional recovery is 
considered as a good example of postlesional plasticity. Vestibular compensation is based on various plasticity mechanisms to restore a balanced activity between bilateral vestibular complexes in the brainstem [1-3].

Pharmacological modulation of the level of excitability or neurogliogenesis in the deafferented vestibular nuclei (VN) modifies the kinetics of vestibular functional restoration. Indeed, the pharmacological blocking of SK channels (small conductance calcium-activated potassium) by apamin, which inhibits the hyperpolarization phase of the action potential, facilitates the restoration of posturo-locomotor function and gaze stabilization [4]. Among the numerous mechanisms of plasticity promoting vestibular compensation, we have demonstrated that a unilateral vestibular neurectomy (UVN) induces a reactive neurogenesis in the deafferented vestibular nuclei of adult cats and rats [5-10]. Continuous intracerebroventricular administration of an antimitotic drug immediately after UVN completely blocks cellular proliferation and neurogliogenesis and delays the posturo-locomotor function recovery drastically [5]. Conversely, increasing cell proliferation and survival with a continuous infusion of brain derived neurotrophic factor (BDNF) immediately after UVN accelerates the recovery of balance and posture, while blocking BDNF-TrkB signaling significantly reduces cell proliferation and prevents postural locomotor recovery in animals with vestibular injuries [8]. These data indicated that the priority of the deafferented vestibular environment after UVN is to promote both the restoration of homeostatic excitability between homologous $\mathrm{VN}$ and the expression of neurogliogenesis for vestibular functional recovery.

Interestingly, thyroid hormones $(\mathrm{TH})$ can promote these two important mechanisms, which are essential for vestibular functional recovery. TH signaling governs many aspects of neurogenesis, including proliferation, survival, migration, differentiation, and maturation of neuronal and glial cells [11-14]. Thyroxine (T4) or triiodothyronine (T3) injections have been shown to increase the expression of BDNF in different pathological models (stroke [15,16], Alzheimer's disease [17], and axotomy [18]). In addition, several studies have demonstrated that TH treatment after traumatic brain injury reduces lesion size, inflammation, and promotes neurogenesis and neuronal survival to improve functional recovery through genomic and non-genomic actions (for review see $[19,20]$ ). Finally, even though the molecular events by which TH regulate energy metabolism are still not fully understood [21-23], this essential function could rebalance the activity between the two homologous VN and promote vestibular compensation. Based on all this evidence, TH are likely candidates to alleviate acute vestibular syndrome and facilitate vestibular compensation.

The aim of our study was to determine whether short-term pharmacological treatment with L-thyroxine following UVN in adult rats affects the time course of vestibular functional recovery and post-lesion plasticity mechanisms in the deafferented VN.

\section{Materials and Methods}

\subsection{Animals}

The experiments were performed on 28 adult Long Evans rats (250/300 g) originating from our own breeding, from parents obtained from Charles River (St Germain sur l'Arbresle, France). All experiments were performed in accordance with the European Union 2010/63/EU Directive and under the veterinary supervision and control of the National Ethical Committee (French Agriculture Ministry Authorization: B13-055-25). The present study was specifically approved by the Neurosciences Ethic Committee $\mathrm{N}^{\circ} 71$ of the French National Committee of animal experimentation. Every attempt was made to minimize both the number and the suffering of animals used in this experiment. The animals were housed in a large, confined space with $12 \mathrm{~h}-12 \mathrm{~h}$ diurnal light variations and free access to food and water. 


\subsection{Unilateral Vestibular Neurectomy}

Animals were subjected to a left-side vestibular nerve section $(n=24)$, following the surgical procedure previously reported in the literature [24]. Thirty minutes after a subcutaneous injection of buprenorphine (Buprecare ${ }^{\circledR} ; 0.02 \mathrm{mg} / \mathrm{kg}$ ), the rats were placed in the anesthesia induction box and left for $5 \mathrm{~min}$ (isoflurane concentration $4 \%$ ). Once they were deeply anesthetized, they were intubated and, during the surgery, the anesthesia was maintained at an isoflurane concentration of 3\%. A tympanic bulla approach gave access to the vestibular nerve: the cervical muscular planes were dissected leading to the tympanic bulla, which was widely drilled to expose the stapedial artery and the promontory containing the cochlea. The cochlea was drilled, exposing the cochlear nerve. The cochlear nerve meatus was enlarged with a needle leading to the vestibulocochlear nerve, which was sectioned at its entry into the brainstem after aspiration of Scarpa's ganglion. The wound was closed using a stapler. Before awakening, the animals received either an intraperitoneal injection of $0.9 \% \mathrm{NaCl}$ (UVN-NaCl group) or a solution of thyroxine (UVNT4 group, $10 \mu \mathrm{g} / \mathrm{kg}$ ). A solution of Ringer Lactate (Virbac, Carros, France; $10 \mathrm{~mL} / \mathrm{kg}$ ) was also administered subcutaneously in order to alleviate the dehydration resulting from the inability of the animal to drink normally as a result of the injury.

The success of the surgery was attested at the behavioral level by the presence of a characteristic vestibular syndrome and at the histological level by the observation of the full section of the 8th cranial nerve between Scarpa's ganglion and VN in the brainstem under optical microscopy (see [24] for details).

\subsection{Criteria for Exclusion}

Animals were excluded from the study if the following symptoms were observed:

- $\quad$ loss of body weight equal to more than $20 \%$ of the pre-operative value.

- $\quad$ if the facial nerve had been sectioned.

- abnormalities in behavioral scoring, i.e., inability of the animal to stand on all four paws after 5 days post-UVN, convulsions, hemiataxia, etc.

Based on these criteria, one animal of the UVN-T4 group was excluded.

\subsection{Study Design}

Rats were randomly assigned to the following groups:

Non-UVN rats: Control rats were perfused transcardially with saline followed by $4 \%$ paraformaldehyde for pre-operative immunohistochemistry assessment $(n=4)$.

UVN-NaCl group: Rats were subjected to UVN, and saline was administered $(0.3 \mathrm{~mL}$, i.p.) at the end of the surgery and one injection/day during the first 3 days post-lesion $(n=12)$.

UVN-T4 group: Rats were subjected to UVN and L-Thyroxine (Sigma-Aldrich St. Quentin Fallavier, France, Cat\#T2501) was administered (10 $\mu \mathrm{g} / \mathrm{kg}$, i.p.) at both the end of the surgery and one injection/day during the first 3 days post-lesion $(n=12)$. The dose and the administration route used in this study was based on [15].

A part of the UVN-NaCl group and UVN-T4 group was killed at day 3 post-UVN ( $n=4$ /group) or day $30(n=8 /$ group). UVN-NaCl $(n=8)$ and UVN-T4 $(n=8)$ rats underwent behavioral investigation prior to UVN and on days $1,2,3,7,10,14,21$, and 30 post-lesion to evaluate the time course of vestibular functional recovery, received a BrdU injection ( $200 \mathrm{mg} / \mathrm{kg}$, i.p.) on day 3 post-UVN, and were killed at day 30 for cellular investigation. Blinded L-T4 or vehicle injection was given $30 \mathrm{~min}$ before the first behavioral test. UVN-NaCl and UVN-T4 groups first performed video-tracking in the open-field, then weight distribution (Bioseb device), and, finally, support surface area. The behavioral tests were conducted 5 min apart.

To study cell proliferation and short-term effect of L-T4 injections UVN-NaCl $(n=4)$ and UVN-T4 $(n=4)$ rats received a BrdU injection $(200 \mathrm{mg} / \mathrm{kg}$, i.p.) on day 3 post-UVN and were killed $3 \mathrm{~h}$ later. 


\subsection{Qualitative Assessment of the Vestibular Syndrome}

We assessed, qualitatively, the vestibular syndrome following UVN. Behavioral symptoms of vestibular imbalance were scored for 10 components after UVN: the tail-hang test, rearing, grooming, displacement, head-tilt, barrel rolling, retropulsion, circling, and bobbing. The tail-hang test (adapted from [25-27]), quantifies typical vestibulospinal reflexes.

- $\quad$ Tail hanging behavior: Animals were picked up from the ground at the base of the tail and body rotation was scored from 0 point (no rotation) to 3 points (several rotations of $360^{\circ}$ )

- Landing reflex: After animals were picked up from the ground at the base of the tail, we scored the first 3 landings from 0 (presence of a landing reflex on the 3 landings) to 3 points (absence of landing reflex on the 3 landings). When lifted by the tail, control rats exhibit a landing reflex, consisting of forelimb extension, that allows them to land successfully (i.e., they land on all four legs). Rats with impaired vestibular function do not exhibit a forelimb extension, they spin or bend ventrally, sometimes "crawling" up toward their tails, causing them to miss their landings.

- $\quad$ Rearing: the ability of the rat to rear was scored from 0 point (rearing is observed) to 1 point (rearing is absent)

- Grooming: the ability of the rat to groom correctly were scored as follows: 0 point (correct grooming of full body) 1 point (grooming of the face, belly, and flanks but not the base of the tail), 2 points (grooming of the face and belly), 3 points (grooming of the face), 4 points (inability of the animal to groom itself)

- Displacement: quality of the displacement of the rat was scored from 0 (displacement of the rat with no visible deficit) to 3 points (several deficits in the displacement of the rat)

- Head tilt was scored by estimating the angle between the jaw plane and the horizontal with 0 points (absence of a head-tilt) to 3 points (for a $90^{\circ}$ angle)

- Barrel rolling was scored as follows: 0 points (absence of barrel rolling), 1 point (barrel rolling evoked by an acceleration in the vertical axis of the rat in our hand), 2 points (spontaneous barrel rolling)

- Retropulsion characterizes backwards movements and was scored from 0 (absence of retropulsion) to 1 point (presence of retropulsion)

- Circling was scored from 0 point (absence of circling behavior) to 1 point (presence of circling behavior)

- $\quad$ Bobbing is related to rapid head tilts to the side and was scored from 0 point (absence of bobbing) to 1 point (presence of bobbing)

A first acquisition was done the day before the lesion, serving as a reference value, and then acquisitions were performed at days (D) 1, 2, 3, 7, 10, 14, 21, and 30 post-lesion.

\subsection{Weight Distribution}

To quantify the postural syndrome following UVN we used a device (DWB1 ${ }^{\circledR}$, Bioseb, Vitrolles, France) measuring the weight distribution at all contact points of the animal's body with the ground. This apparatus has previously been described for the assessment of postural instabilities in the same model of vestibular loss [28]. The device consists of a Plexiglas cage $(25 \times 25 \mathrm{~cm})$ in which the animal can move freely. The floor of this cage is fully covered with a plate with 2000 force sensors. Sensors detect vertical pressure at a sample rate of $30 \mathrm{Hertz}$. The sensors are connected to an electronic interface that converts the current flowing through it into a measure of weight, the whole being connected to a computer. The cage is closed by a lid on which is attached a high definition camera, also connected to the computer through a USB cable.

The analyses enabled the acquisition of a range of parameters calculated automatically by the software (for details, see [28]). Based on previous results [28], we chose to analyze only the weight distributed on the lateral axis, which allows for the determina- 
tion of how the animal distributes its weight between the left and right paws in order to maintain balance.

For each acquisition session, the rat was placed in the device for $5 \mathrm{~min}$ and could move freely. The pre-operative session was recorded the day before the surgery, and then the time course of the vestibular syndrome was studied on D1, 2, 3, 7, 10, 14, 21, and 30 post-lesion.

\subsection{Open Field Test}

To quantify the locomotor syndrome following UVN, we used an automated video tracking software (EthoVision ${ }^{\mathrm{TM}}$ XT 14, Noldus, Wageningen, The Netherlands). Animals were individually placed in a square open field $(80 \times 80 \times 40 \mathrm{~cm})$ and were allowed to move freely for $10 \mathrm{~min}$. Their behavior was recorded for $10 \mathrm{~min}$ using a digital camera and analyzed with EthoVision ${ }^{\mathrm{TM}}$ XT 14 software. Position of nose, body center, and tail were automatically detected by video software.

Based on previous results [29], the mean distance travelled, meander, mean locomotor velocity, mean number of high accelerations $\left(>50 \mathrm{~cm} / \mathrm{s}^{2}\right)$, and mean percentage of time spent immobile were quantified (for details, see [29]). To minimize stress, the room was lit as dimly as possible while allowing us to clearly discern the rats. At the beginning of the session, the rat was placed on the right side of the field, head facing the wall. A first acquisition was done the day before the lesion, serving as a reference value, and then acquisitions were performed at D1, 2, 3, 7, 10, 14, 21, and 30 post-lesion.

\subsection{Support Surface}

Static postural deficits and recovery were evaluated by measuring the support surface delimited by the four legs of the rat. The support surface can be regarded as a good estimate of postural control because it reflects the behavioral adaptation of the rat in compensating for the static vestibulospinal deficits induced by the vestibular lesion. To quantify the support surface, rats were placed in a device with a graduated transparent floor that allowed them to be filmed from underneath. A scale drawn on the bottom served to take measurements of the location of the four paws. To avoid measures when the animals were moving, we measured the support surface area when the animal landed. For this purpose, we picked up the animal by the tail and lifted it vertically to a height of about $50 \mathrm{~cm}$ (lift duration 2 s; position holding at upper position: $1 \mathrm{~s}$ ) and dropped it to a height of about $10 \mathrm{~cm}$. When the animal touched the ground, we took a capture of the location of the four paws. Twenty repeated measurements were taken for each rat tested at each time point (pre-lesion, D1, 2, 3, 7, 10, 14, 21, and 30 post-lesion), and an average was calculated for each experimental session. The support surface was measured using a custom written image analysis tool (Matlab ${ }^{\circledR}$, Mathworks, Incs, Natick, MS, USA). Data recorded after UVN were compared to the mean pre-lesion values using individual references, which means each animal acted as its own control.

\subsection{Tissue Preparation}

The rats were deeply anesthetized with a mixture of ketamine 1000/medetomidine and then perfused by intracardiac injection. The intracardiac injection of $400 \mathrm{~mL}$ of isotonic saline $(0.9 \% \mathrm{NaCl})$ was followed by $400 \mathrm{~mL}$ of $4 \%$ paraformaldehyde in $0.1 \mathrm{M}$ phosphate buffer (PB), $\mathrm{pH}$ 7.4. At the end of the perfusion, the brain was extracted from the skull and post fixed overnight at $4{ }^{\circ} \mathrm{C}$ in the same fixative solution as that used during the perfusion. Brains were rinsed and cryoprotected by successive transfers into increasing concentrations $\left(10,20,30 \%\right.$ of sucrose solution in $0.1 \mathrm{M} \mathrm{PB}$ for $72 \mathrm{~h}$ at $\left.4{ }^{\circ} \mathrm{C}\right)$. Brains were rapidly frozen with $\mathrm{CO}_{2}$ gas and cut into serial $40 \mu \mathrm{m}$ frontal section with a cryostat (Leica, Wetzlar, Germany) for immunochemistry. 


\subsection{Immunohistochemistry}

Immunochemical labeling was performed according to previously validated protocols $[7,8,10]$. Cell proliferation was analyzed in groups 1 (UVN-NaCl-D3) and 3 (UVN-T4D3) after injection of BrdU on D3 post-UVN, and the animals were killed $3 \mathrm{~h}$ later. Survival and differentiation of the newly generated cells were analyzed in groups 2 (UVN-NaCl) and 4 (UVN-T4) that were injected with BrdU on D3 post-UVN and killed on D30. Floating brain sections were washed $(3 \times 10 \mathrm{~min})$ with PBS in multi-well plates. Blocking was done by incubation $(1 \mathrm{~h})$ in $5 \%$ BSA and $0.3 \%$ Triton $\mathrm{X}-100$. Slides were incubated overnight at $4{ }^{\circ} \mathrm{C}$ with the following primary antibodies: mouse anti-BrdU (1:100, Dako, Santa Clara, CA, USA), rat anti-BrdU (1:100 Bio-rad, Marnes-la-Coquette, France), mouse anti-NeuN (1:100, Millipore, Burlington, MA, USA), rabbit anti-GFAP (1:200, Dako), rabbit anti-IBA1 (1:2000, Wako, Saitama, Japan), rabbit anti-Olig2 (1:500, Millipore), goat anti-Sox2 (1:100, R\&D Systems Minneapolis, MN, USA), rabbit anti-TR $\alpha$ (1:200, Rockland), rabbit anti-TR $\beta$ (1:200, Invitrogen, Waltham, MA, USA), goat anti-DIO2 (1:200, Invitrogen), and rabbit anti-KCC2 (1:200, Millipore). Fluorescent secondary antibodies (Abcam, Cambridge, UK) were used as follows: Alexa Fluor 594 nm goat anti-rat (1:500), Alexa Fluor 594 nm donkey anti-goat (1:500), Alexa Fluor 488 nm donkey anti-rabbit (1:500), and Alexa Fluor 488 nm donkey anti-mouse (1:500) for $2 \mathrm{~h}$ at room temperature. Finally, brain sections were mounted onto SuperFrost/Plus glass slides (Fischer, Innviertel, Austria) and air-dried before being mounted with Roti ${ }^{\circledR}$ Mount FluorCare antifade reagent with the nuclear marker DAPI (Carl Roth, Karlsruhe, Germany).

\subsection{Cells Count and Statistical Analysis}

For quantification of cells expressing specific markers, 1 in 12 serial sections starting at the beginning of the vestibular nuclei (relative to bregma, $-9.84 \mathrm{~mm}$ ) to the end of the vestibular nuclei (relative to bregma, $-13.08 \mathrm{~mm}$ ), according to the rat brain stereotaxic atlas [30], were used. Only sections of the medial vestibular nucleus (MVN) on the lesioned (left) side were evaluated. Quantification of $\mathrm{BrdU}^{+} \mathrm{NeuN}^{+}, \mathrm{GFAP}^{+}, \mathrm{IBA}^{+}, \mathrm{Olig}^{+}$, Sox2 ${ }^{+}$, thyroid hormone receptor alpha ${ }^{+}(\mathrm{TR} \alpha)$, and thyroid hormone receptor beta ${ }^{+}(\mathrm{TR} \beta)$ cells was counted using confocal imaging with a Zeiss LM 710 NLO laser scanning microscope equipped with a $63 \times / 1.32 \mathrm{NA}$ oil immersion lens. For each marker, immunoreactive positive cells in the MVN were counted using an integrated microscopic counting chamber that delineated the region of interest by a square of $425.10 \mu \mathrm{m}^{2}$. The average cell counts from the sections were used for statistical analysis.

\subsection{Quantification of KCC2}

A custom program written in Matlab ${ }^{\circledR}$ (Mathworks, Incs) was developed to analyze the membrane fluorescence of KCC2 [31]. The background or non-specific immunofluorescence was evaluated by calculating the mean florescence in a selected area devoid of neurons or other immunolabeled structures. In this region, we then established a threshold equal to the mean immunofluorescence plus three times the standard deviation. All data were subtracted from this threshold value and only positive values were conserved for further analysis. A region of interest was then drawn around the plasma membrane of a neuron. The program calculated the mean membrane fluorescence of each cell body in the region of interest over data that were above $20 \%$ of the maximum value. This threshold was used to ensure that only pixels belonging to the plasmatic membrane were counted. The mean membrane fluorescence of the measured neurons enables us to estimate the level of membrane expression of KCC2. A low membrane expression of KCC2 is correlated with an increase in intracellular $\mathrm{Cl}^{-}$ion concentration. The consequence of this increase is a decrease in the efficacy of GABAergic inhibition and, in the most severe cases, an exit of $\mathrm{Cl}^{-}$ions from the cell by the action of $\mathrm{GABA}$ on its $\mathrm{GABA}_{\mathrm{A}}$ receptor, thus converting GABAergic neurotransmission from inhibitory to excitatory [32]. 


\subsection{Cytochrome Oxidase Histochemistry}

Metabolic activity in the lateral vestibular nuclei was assessed by means of cytochrome oxidase (CO) labeling on series of $40 \mu \mathrm{m}$-thick coronal frozen sections. Slides were incubated overnight in the dark in a solution of $0.1 \mathrm{M}$ phosphate buffer ( $\mathrm{pH} 7.4)$ containing $10 \mathrm{mg}$ of DAB (Tablet \#D5905 Sigma-Aldrich, St. Quentin Fallavier, France) and $30 \mathrm{mg}$ horse-heart cytochrome c (\#C2506, Sigma-Aldrich, France) per 50 mL, stirred continuously (Sigma-Aldrich, St. Quentin Fallavier, France for all the chemical products). The slides were then washed two times in buffer $(2 \times 5 \mathrm{~min})$, dehydrated in successive ethanol and xylene baths, and coverslipped with DPX. Images of the lateral vestibular nuclei, identified by the rat brain stereotaxic atlas [30], were collected and we counted the number of neurons positive to CO labeling only in the lateral vestibular nuclei.

\subsection{Statistical Analysis}

We performed all statistical analyses using GraphPad Prism software (version 7, GraphPad Software, San Diego, CA, USA). Summary graphs are all shown as mean $\pm \mathrm{SEM}$. A two-way repeated measures ANOVA with a post-hoc Bonferroni's multiple comparison test were used to determine statistical differences between the treatments ( $\mathrm{UVN}-\mathrm{NaCl}$ and UVN-T4) for behavioral data. The statistical analyses of the cellular data were evaluated by two-way ANOVA to determine the effects of the group (UVN-NaCl and UVN-T4) and the post-operative time (Pre-op, D3 or D30) on $\mathrm{BrdU}^{+}, \mathrm{NeuN}^{+}, \mathrm{GFAP}^{+}, \mathrm{IBA}^{+}, \mathrm{Olig}^{+}$, Sox2 ${ }^{+}$, $\mathrm{TR} \alpha^{+}, \mathrm{TR} \beta^{+}$, and $\mathrm{CO}^{+}$cells to determine whether there were any interactions between these variables. ANOVA was followed by post hoc analysis with the Tukey's test. $p$ values of $<0.05$ were considered as statistically significant. ${ }^{*} p<0.05,{ }^{* *} p<0.01,{ }^{* * *} p<0.001$.

\section{Results}

\subsection{L-Thyroxine Treatment Reduced Postural Vestibular Deficits}

After UVN, animals showed severe signs of posturo-locomotor alterations characteristic of vestibular syndrome that can be scored using different tests. L-T4 $(10 \mu \mathrm{g} / \mathrm{kg}$, i.p.) or $0.9 \% \mathrm{NaCl}$ (vehicle, in equivalent volume, i.p.) was administered to rats at the end of the UVN procedure and a single injection per day over the first 3 days, $30 \mathrm{~min}$ before behavioral tests (Figure 1a).

These behavioral deficits were assessed at several time points over a period of 30 days using a qualitative 'vestibular score' scale (see Methods section). In both the UVN-NaCl and UVN-T4 groups, the mean vestibular score peaked on D1 (UVN-NaCl: $17 \pm 0.53$; UVN-T4: $12 \pm 0.53$ ) and never completely disappeared at up to 30 days after the lesion (Figure 1b). From D1 until D7, UVN-T4 treated animals had a lower vestibular score than UVN-NaCl animals $(p<0.0001)$.

Unilateral vestibular lesion also results in an increase in the support surface delimited by the animal's four paws. This parameter is a good estimate of postural stability and restoration of balance $[4,8,33,34]$. When we compared the support surface area of each group between the pre-operative values and the values obtained after UVN (D1-D30), we observed that the UVN-NaCl group had significantly increased their support surface area the first 3 days following vestibular lesion (D1 to D3: $p<0.001$ ) and reached pre-operative control values from D7 until D30 (Figure 1c). In contrast, the UVN-T4 group significantly increased their support surface area only at D1 after vestibular lesion $(p<0.001)$ restoring to pre-operative control values from D2. Comparison between groups showed that support surface area in the UVN-T4 group was reduced on D2 and D3 when compared to a saline injection after UVN $(p<0.01)$.

To further study postural impairment after UVN and the improvement by L-T4 treatment, we next tested the weight distribution of rats on the lateral axis. As shown in previous reports [28,33], before UVN, rats distributed their weight symmetrically between the right and the left sides (Figure 1d). After UVN, UVN-NaCl rats increased the weight applied on their ipsilesional paws, resulting in a postural asymmetry that reached $8 \%$ at D7 and increased to 11\% at D30 (D7: $p<0.05$; D30: $p<0.001$; Figure 1d). In the UVN-T4 group, 
the postural asymmetry induced by UVN was not present (D7 and D30: $p=\mathrm{ns}$ ). Taken together, these results suggest that L-T4 treatment improves the restoration of postural deficits induced by UVN.

a

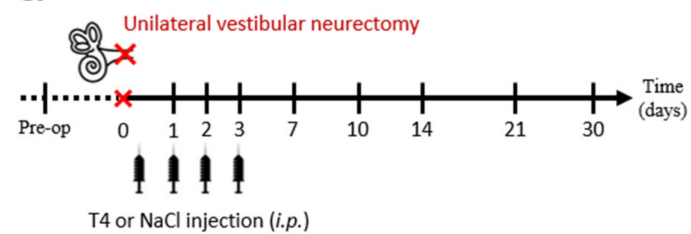

b

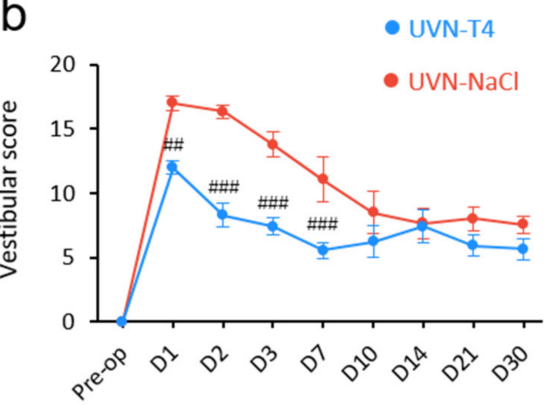

C
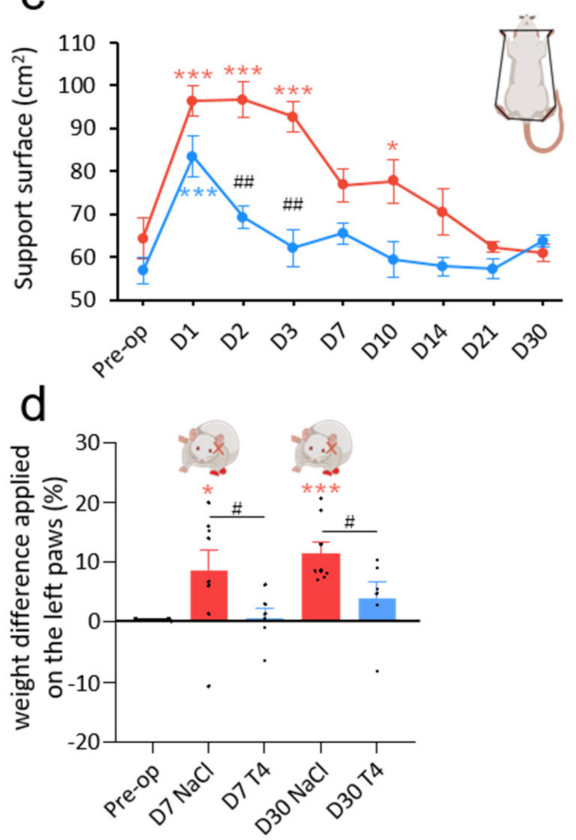

Figure 1. L-T4 treatment accelerates recovery from UVN-induced postural alterations. (a) Study design used to assess the behavioral effects of acute L-thyroxine (L-T4) treatment after unilateral vestibular neurectomy (UVN). UVN-T4 group received L-T4 injections (10 $\mu \mathrm{g} / \mathrm{kg}$ dissolved in saline, i.p.) and $\mathrm{UVN}-\mathrm{NaCl}$ group received $0.9 \% \mathrm{NaCl}$ (vehicle, in equivalent volume, i.p.) at the end of the UVN and one injection/day during the first 3 days post-lesion. (b) Curves illustrating the time course (on the abscissae) of the vestibular syndrome (vestibular score on the ordinates) of UVN-NaCl (red) and UVN-T4 (blue) groups. (c) Curves indicating the mean post-operative recovery of the support surface of UVN-NaCl and UVN-T4 groups. (d) Histograms illustrating the weight distribution on the lateral axis of $\mathrm{UVN}-\mathrm{NaCl}$ and $\mathrm{UVN}-\mathrm{T} 4$ groups. Error bars represent SEM. A significant difference from the pre-operative value is indicated by * in red for $\mathrm{UVN}-\mathrm{NaCl}$ group. A significant difference from the pre-operative value is indicated by * in blue for UVN-T4 group. A significant difference between UVN-NaCl $(n=8)$ and UVN-T4 $(n=7)$ group is indicated with \# in black ${ }^{*} p<0.05,{ }^{* *} p<0.01$, $* * * p<0.001$; repeated measure two-way ANOVA and Bonferroni's post hoc tests). 


\subsection{L-Thyroxine Treatment Improved Locomotor Recovery after UVN}

To investigate other behavioral alterations induced by L-T4 treatment after UVN, we conducted locomotor behavioral test batteries. We previously reported that UVN resulted in significant changes in locomotor activity [29]. In the open field test, UVN-T4 rats significantly reduced their total distance travelled only on D1 $(p<0.05)$ and did not present a hyperactivity phase from D10 to D30, as was observed in the UVN-NaCl group (Figure 2a,b). In contrast, the total distance travelled was remarkably diminished the first 3 days after UVN for the UVN-NaCl group (D1: $p<0.001 ; \mathrm{D} 2: p<0.01 ; \mathrm{D} 3: p<0.05$ ) and conversely, increased from D10 until D30 (D10 to D30: $p<0.001$ ). Similarly, the immobility time of UVN-NaCl rats increased the first 3 days after the lesion, with a maximum on D1 (D1 to D2: $p<0.001$; D3: $p<0.01$ ) before returning to pre-operative control values from D7 (Figure 2c). Immobility time in the UVN-T4 group increased only on D1 $(p<0.001)$, returned to control values by D2, and was reduced on D1 and D2 when compared to UVN-NaCl group (D1: $p<0.001$; D2: $p<0.05$ ). Mean velocity of the UVN-NaCl group (Figure $2 \mathrm{~d}$ and Supplementary Video S1) was reduced the first 3 days after UVN (D1 and D2: $p<0.001$; D3: $p<0.01$ ) and increased from D10 to D30 (D10 to D30: $p<0.001$ ). UVN-T4 rats did not present a reduction of velocity the first 3 days after UVN (Figure 2d and Supplementary Video S2) and were significantly different from UVN-NaCl rats on D1 and D2 $(p<0.01)$. However, the UVN-T4 group also adopted the locomotor strategy of increasing their velocity from D10 to D30 (D10 to D21: $p<0.05$; D30: $p<0.01$ ). In the same way, the number of high accelerations (Figure 2e) of the UVN-NaCl group was almost absent the first 3 days (D1 to D3: $p<0.001$ ) and increased from D14 to D30 (D14: $p<0.01$; D21 and D30: $p<0.05$ ). In contrast, the UVN-T4 group was still able to achieve high accelerations during the first 3 days post-UVN, although with reduced accelerations on D1 and D2 when compared to pre-operative values (D1: $p<0.001$; D2: $p<0.05)$. Furthermore, UVN-T4 treated rats more quickly increased their high accelerations (D7 vs. D14) when compared to the UVN-NaCl group (D7: $p<0.01$ ). The number of high accelerations between groups was significantly different on D3 and D7 post-UVN (D3: $p<0.05$; D7: $p<0.01$ ). Finally, vestibular disorders induce imbalance and stumbling, which leads to difficulty in walking straight. The 'meander' parameter from Ethovision XT14 allowed us to quantify the difficulty of walking (Figure 2f). While animals injected with a saline solution had a drastically unstable gait on D1 post-UVN (D1: $p<0.001)$, animals injected with L-T4 did not exhibit significant gait instability. Collectively, these findings suggest that short-term L-T4 treatment reduces the vestibular syndrome after a unilateral vestibular loss and promotes functional recovery (Supplementary Videos S1 and S2).

\subsection{Presence of Thyroid Hormone Receptors and Thyroxine Deiodinase 2 in the Vestibular Nuclei}

The results obtained from behavioral analysis after UVN show that L-T4 treatment improved the recovery of vestibular functions, and suggest an effect of L-T4 in the vestibular nuclei (VN). The genomic effects of $\mathrm{TH}$ are mediated by the interaction of $\mathrm{T} 3$, the active form of $\mathrm{TH}$, with $\mathrm{TH}$ receptors acting as transcriptional factors regulating the expression of several genes $[21,35]$. A first approach to understand the mechanism of action of TH in the $\mathrm{VN}$ consisted of analyzing the expression of $\operatorname{TR} \alpha, \mathrm{TR} \beta$, and iodothyronine deiodinase type 2 (DIO2), which is responsible for converting T4 into T3 [36-39]. We found that $\mathrm{VN}$ of adult rodent brain expressed both TR $\alpha$ and TR $\beta$, as well as the enzyme DIO2 (Figure 3a). We also observed SOX2-positive $\left(^{+}\right.$) and TR-negative $\left({ }^{-}\right)$cells and vice versa (SOX2 ${ }^{-} / \mathrm{TR} \alpha^{+}$cells, indicated by arrows; Figure $3 \mathrm{~b}$ ), which is strikingly similar to the pattern of neural stem cells reported in the subventricular niche [40]. This pattern confirms our previous results [10], revealing for the first time the presence of local neural stem cells in the vestibular nuclei of control rats. Taken together, these observations suggest that vestibular nuclei cells are able to provide their own intracellular T3 and display suitable molecular equipment to engage a genomic effect of thyroid hormones. Furthermore, the expression of both SOX2 and TR $\alpha$ in the vestibular nuclei may suggest an action of L-T4 on neural stem cell commitment and differentiation [40]. 


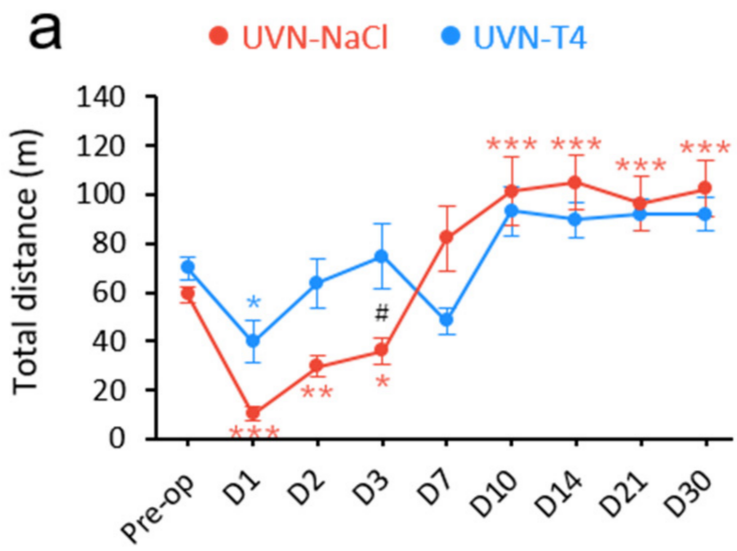

C

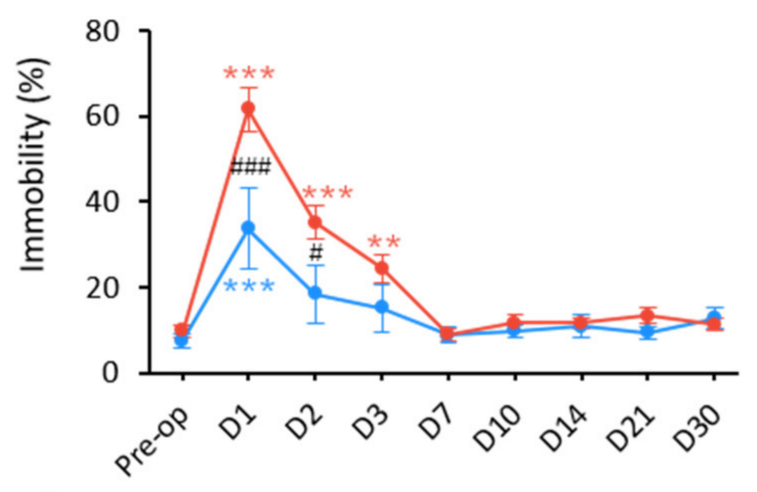

e

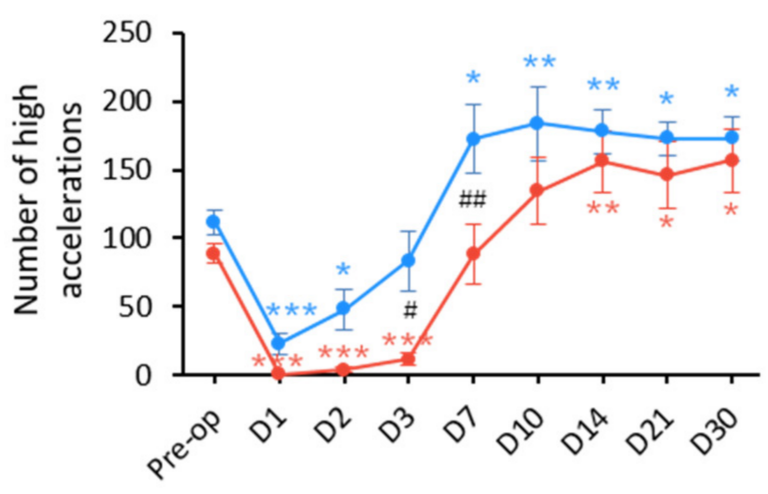

b
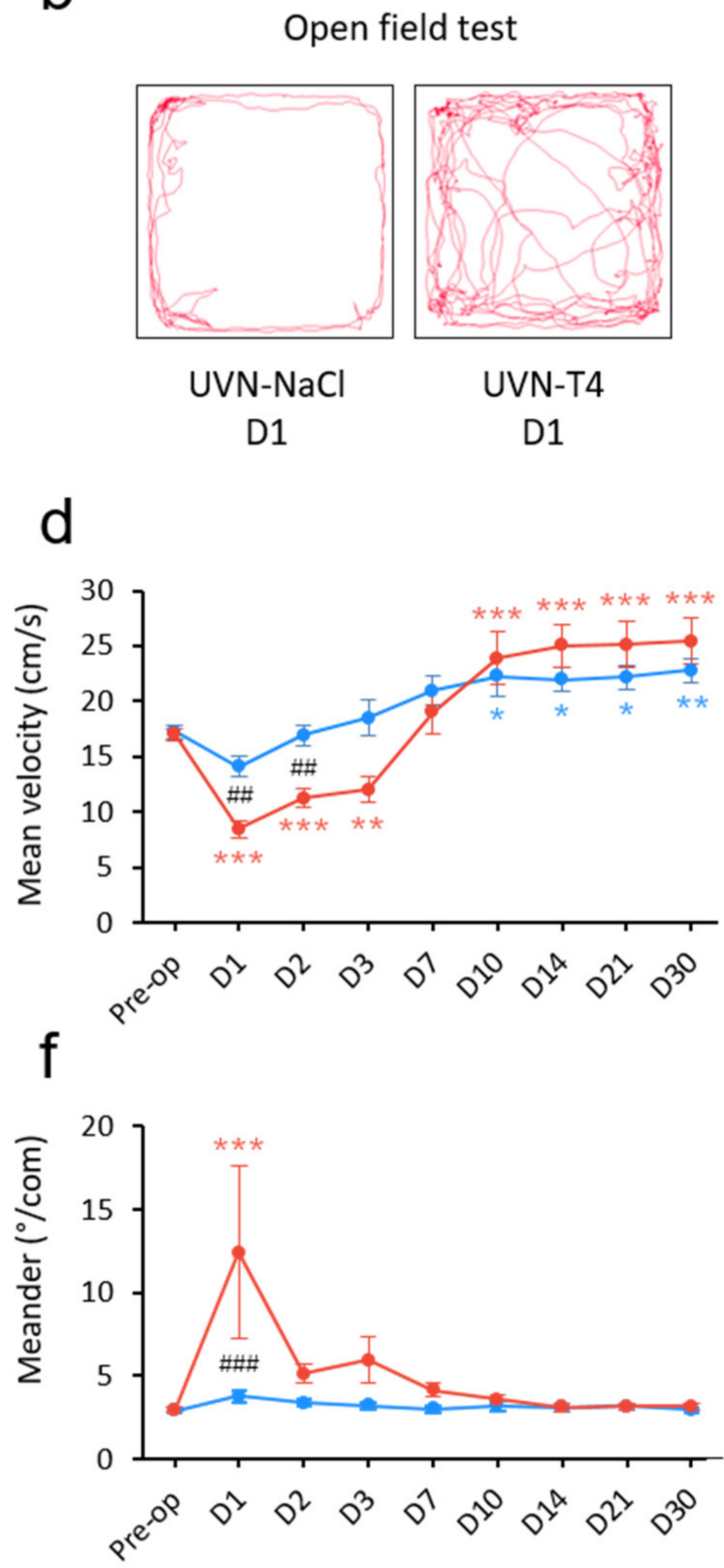

Figure 2. L-T4 treatment accelerates recovery from UVN-induced locomotor alterations. (a) Curve illustrating the mean post-operative recovery of the total distance moved by UVN-NaCl and UVN-T4 rats in the open field. (b) Video-tracked path of a UVN-NaCl and a UVN-T4 rat one day after UVN in the open field over a 10 min period. (c) Curves illustrating the kinetics of the percentage of time when the animal is immobile of $\mathrm{UVN}-\mathrm{NaCl}$ (red) and UVN-T4 (blue) groups. (d) Curves illustrating the kinetics of the mean velocity $(\mathrm{cm} / \mathrm{s}$ ) of the animals (calculated from the center-point) of $\mathrm{UVN}-\mathrm{NaCl}$ and UVN-T4 groups. (e) Curves illustrating the kinetics of the mean number of high accelerations (above $50 \mathrm{~cm} / \mathrm{s}^{2}$ ) of the animals (calculated from the center point) of UVN-NaCl and UVN-T4 groups. (f) Curves illustrating the mean post-operative recovery of meander (sinuous trajectory) in the UVN$\mathrm{NaCl}$ and UVN-T4 groups. Error bars represent SEM. A significant difference from the pre-operative value is indicated by * in red for $\mathrm{UVN}-\mathrm{NaCl}$ group. A significant difference from the pre-operative value is indicated by * in blue for UVN-T4 group. A significant difference between $\mathrm{UVN}-\mathrm{NaCl}(n=8)$ and UVN-T4 $(n=7)$ group is indicated with \# in black $\left({ }^{*} p<0.05,{ }^{* *} p<0.01,{ }^{* * *} p<0.001\right.$; repeated measure two-way ANOVA and Bonferroni's post hoc tests). 
a

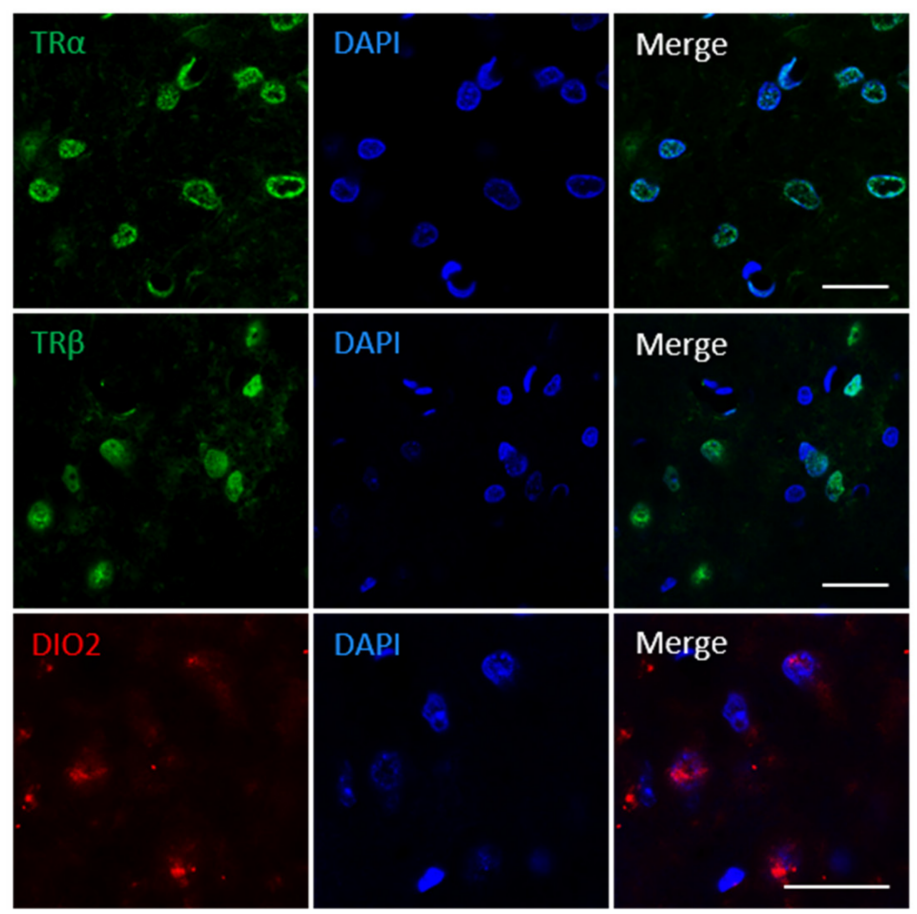

b
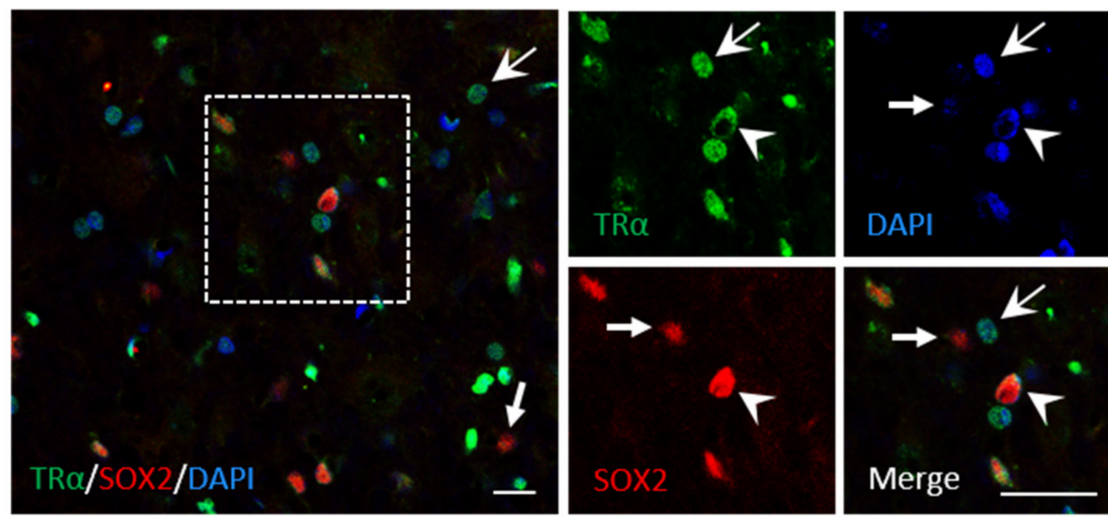

Figure 3. Presence of $\operatorname{TR} \alpha, \operatorname{TR} \beta$ and Dio2 in the vestibular nuclei of control rats. (a) confocal immunostaining images confirming the presence of $\operatorname{TR} \alpha$ (green), $\mathrm{TR} \beta$ (green), and Dio2 (red) in the vestibular nuclei of control animals (without UVN). (b) Colocalization of TR $\alpha$ (green), SOX2 (red), and DAPI (blue) if cells in the vestibular nuclei. Head arrows indicate TR $\alpha \mathrm{PL} / \mathrm{SOX} 2^{+} / \mathrm{DAPI}^{+}$ cells, arrows with tail indicate $\mathrm{TR} \alpha^{+} / \mathrm{SOX}^{-} / \mathrm{DAPI}^{+}$cells, and small arrows with a tail indicate $\mathrm{TR} \alpha^{-} / \mathrm{SOX}^{+} / \mathrm{DAPI}^{+}$cells. Scale bar $=20 \mu \mathrm{m}$.

\subsection{L-Thyroxine Up-Regulates TR $\alpha$ and Block the Up-Regulation of SOX2 in the Deafferented Vestibular Nuclei}

Interestingly, $\mathrm{TR} \alpha^{+}$cells increased significantly at D3 after UVN only in animals treated with L-T4 when compared to basal levels or to the D3 UVN-NaCl group (Pre-op vs. D3 T4: $p<0.001$; D3 NaCl vs. D3 T4: $p<0.01$; Figure 4a,b). However, the up-regulation of $\mathrm{TR} \alpha$ was present in both groups at D30 after UVN (UVN-NaCl: $p<0.01$; UVN-T4: $p<0.05$ ). Conversely, in UVN-T4 group, the number of SOX2 ${ }^{+}$cells at D3 post-UVN remained at the basal levels, while it increased in the UVN-NaCl group $(p<0.05$; Figure $4 \mathrm{a}, \mathrm{c})$. As described in the subventricular neurogenic niche [40], the decreased number of SOX2 ${ }^{+}$and the increased number of TR $\alpha^{+}$cells in the vestibular nuclei suggests that L-T4 injections may increase cell proliferation and neural differentiation by repressing the action of Sox 2 
on activated vestibular neural stem cells [10]. To confirm this hypothesis, we evaluated cell proliferation with a single injection of $\operatorname{BrdU}(200 \mathrm{mg} / \mathrm{kg}) 3 \mathrm{~h}$ prior to intracardiac perfusion at D3 post-UVN and evaluated the cellular fate of the newly generated cells at D30 (see study design in Figure 5a).

a

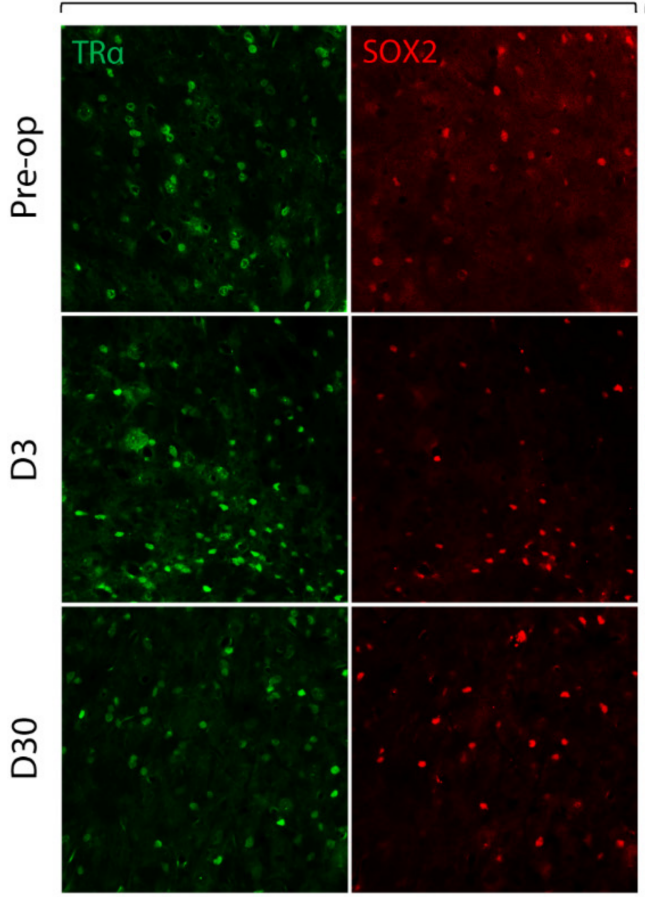

UVN-T4

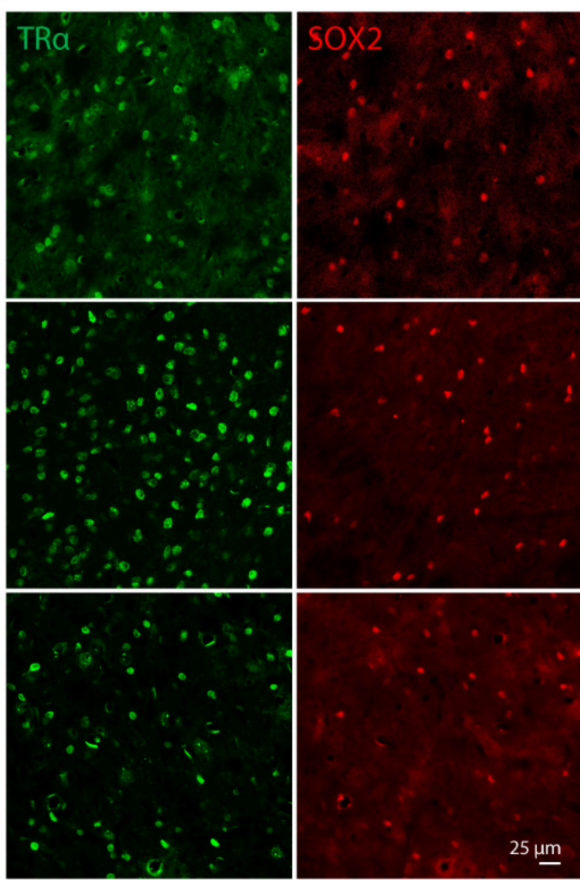

b

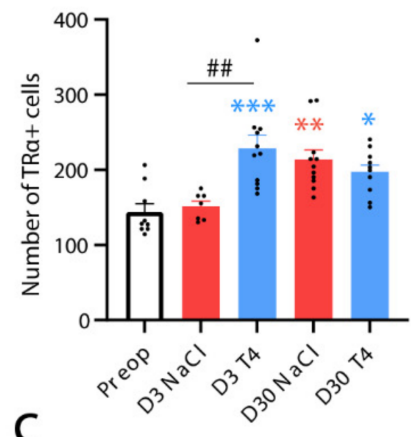

C

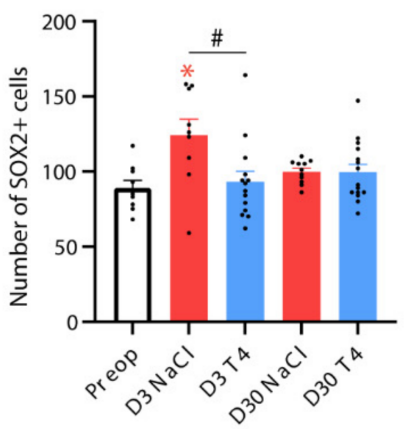

Figure 4. L-T4 treatment prevents the positive regulation of $\mathrm{SOX}_{2}^{+}$cells and increased the number of TR $\alpha^{+}$cells three days after UVN in the deafferented medial vestibular nucleus. (a) Confocal immunostaining images of TR $\alpha^{+}$(green) and SOX2 ${ }^{+}$(red) cells in the deafferented medial vestibular nucleus (MVN) before the lesion (pre-op), three days (D3) or thirty days (D30) after UVN for UVN$\mathrm{NaCl}$ and UVN-T4 groups. (b) Quantitative assessment of the effect of UVN and L-T4 treatment on the number of TR $\alpha^{+}$cells in the deafferented MVN. (c) Quantitative assessment of the effect of UVN and L-T4 treatment on the number of SOX2 ${ }^{+}$cells in the deafferented MVN. Error bars represent SEM. A significant difference from the pre-operative value is indicated by * in red for $\mathrm{UVN}-\mathrm{NaCl}$ group. A significant difference from the pre-operative value is indicated by * in blue for UVN-T4 group. A significant difference between $\mathrm{UVN}-\mathrm{NaCl}$ and UVN-T4 group is indicated with \# in black (* $p<0.05,{ }^{* *} p<0.01,{ }^{* * *} p<0.001$; one-way ANOVA and Tuckey's post hoc tests). Scale bar $=25 \mu \mathrm{m}$.

\subsection{L-Thyroxine Increases Cell Proliferation and Alters the Cellular Fate of Newly Generated Cells in the Deafferented Vestibular Nuclei}

Unilateral vestibular loss induces numerous plastic events in the vestibular nuclei [3]. Among these events are strong cell proliferation, glial reaction, and reactive neurogenesis after UVN, which are all involved in vestibular compensation [5-8,41]. We recently demonstrated that quiescent neural stem cells in the MVN are reactivated after UVN [10] and that, interestingly, TH plays an important role in the proliferation and differentiation of neural stem cells [40,42]. Since TH affects glial cells' function and governs many aspect of neurogenesis $[11,12,39,43]$, we investigated whether L-T4 injections modulate reactive neurogenesis and glial reaction in the vestibular nuclei after UVN. 
a

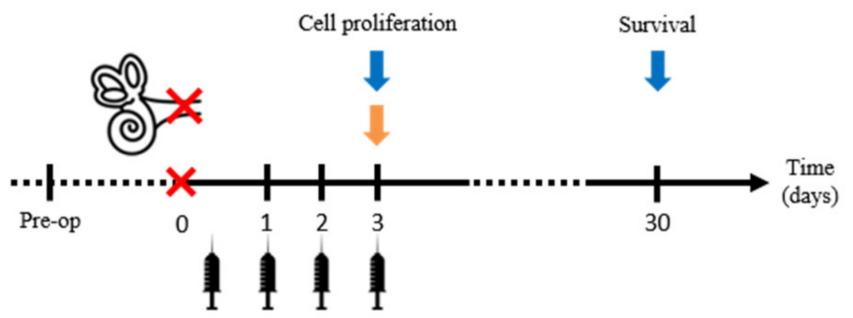

b

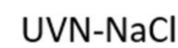

UVN-T4

C

\section{Unilateral vestibular neurectomy \\ T4 or $\mathrm{NaCl}$ injection (i.p.) \\ 1 BrdU injection (i.p.) \\ 1 Perfusion (cellular investigation)}

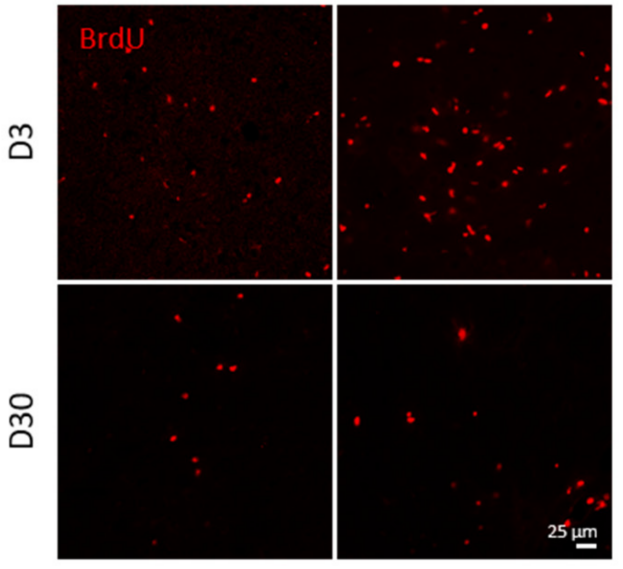

d

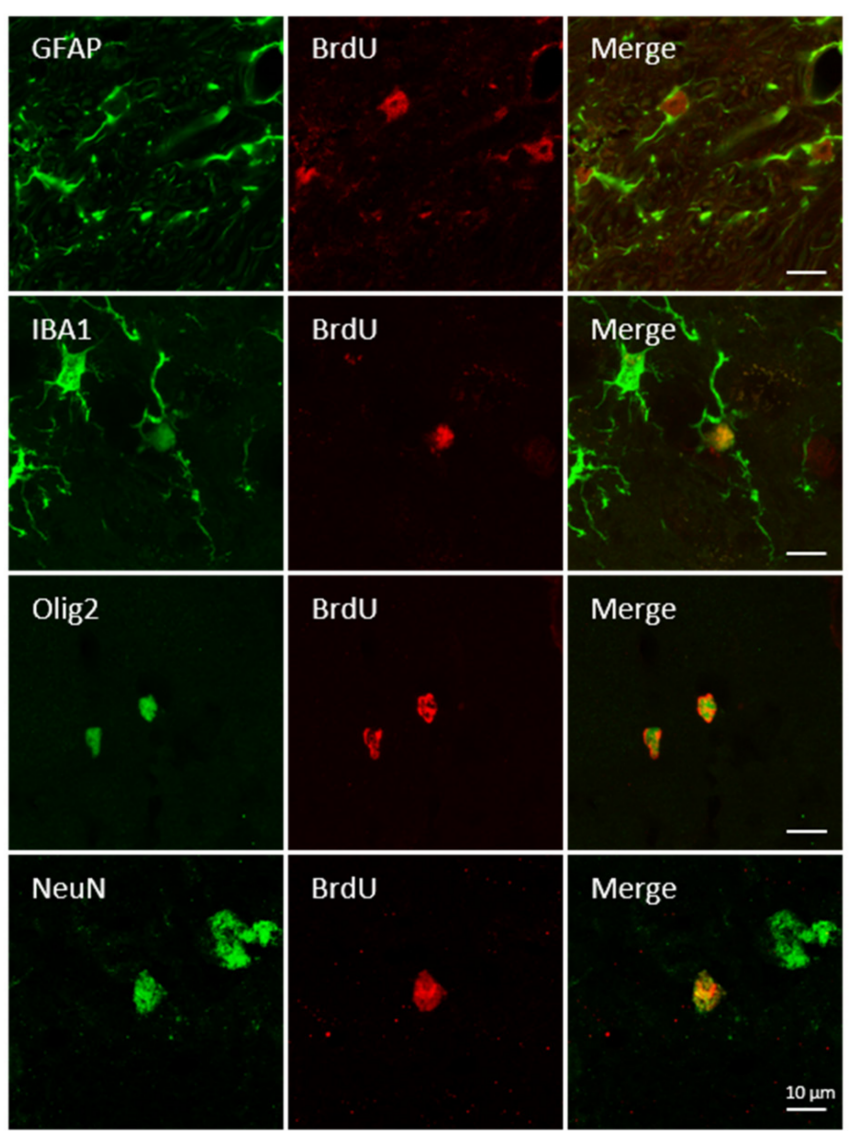

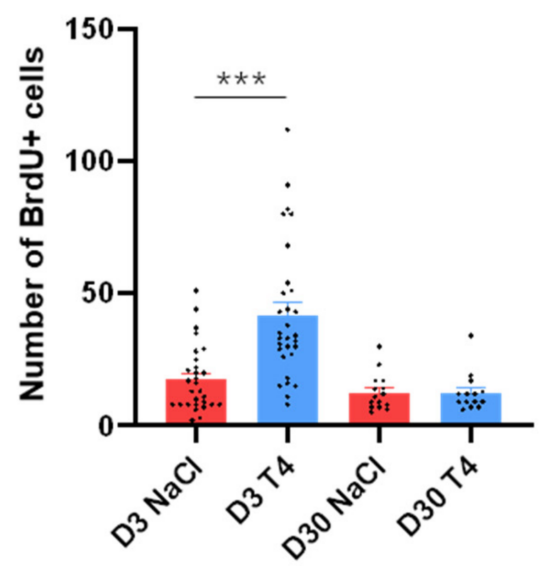

e

Percentage of cell differentiation in UVN-NaCl group

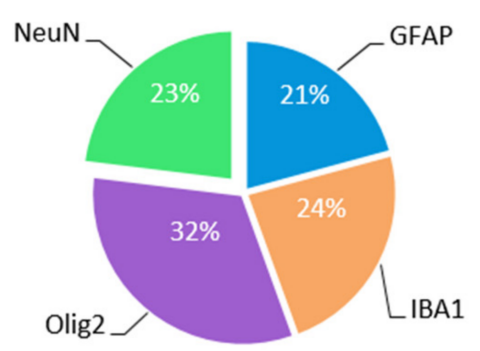

f

Percentage of cell differentiation in UVN-T4 group

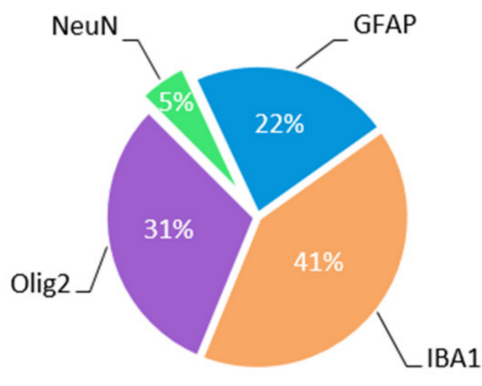

Figure 5. L-T4 treatment modulates cell proliferation and neurogenesis after UVN. (a) Study design used to assess cell proliferation and survival of the newly generated cells after unilateral vestibular 
neurectomy (UVN) and L-thyroxine (L-T4) treatment. UVN-T4 group received L-T4 injections $(10 \mu \mathrm{g} / \mathrm{kg}$, i.p.) and the $\mathrm{UVN}-\mathrm{NaCl}$ group received $0.9 \% \mathrm{NaCl}$ (vehicle, in equivalent volume, i.p.) at the end of the UVN and one injection/day during the first 3 days post-lesion. At day 3 , animals received a BrdU injection ( $200 \mathrm{mg} / \mathrm{kg}$, i.p.) and were perfused either $3 \mathrm{~h}$ later to evaluate cell proliferation, or on day 30 , to investigate survival and differentiation of the newly generated cells. (b) Confocal immunostaining images of $\mathrm{BrdU}^{+}$cells in the deafferented medial vestibular nucleus (MVN) before the lesion (pre-op), three days (D3) and thirty days (D30) after UVN for UVN-NaCl and UVN-T4 groups. Scale bar $=25 \mu \mathrm{m}$. (c) Quantitative assessment of the effect of UVN and L-T4 treatment on the number of $\mathrm{BrdU}^{+}$cells in the deafferented MVN of UVN-NaCl (red, $n=4$ /delay) and UVN-T4 (blue, $n=4$ /delay) groups. ( ${ }^{* * *} p<0.001$; one-way ANOVA and Tuckey's post hoc tests). (d) Maximum intensity projection of Z-stack confocal images of cell differentiation evaluated in the deafferented MVN 30 days after UVN. The BrdU nuclei are in red, and the other markers of differentiation are: GFAP (astrocyte), IBA1 (microglia), Olig2 (oligodendrocytes), and NeuN (neuron) are in green. Scale bar $=10 \mu \mathrm{m}$. (e,f) Proportions of new neurons (green), astrocytes (blue), microglia (orange), and oligodendrocytes (purple) generated in the deafferented $\mathrm{MVN}$ of the UVN-NaCl (e) and UVN-T4 (f) groups 30 days after the lesion.

We evaluated cell proliferation with a single injection of BrdU $(200 \mathrm{mg} / \mathrm{kg}) 3 \mathrm{~h}$ prior to intracardiac perfusion at D3 post-UVN (Figure 5a). The UVN-T4 group increased the mean number of $\mathrm{BrdU}^{+}$cells in the deafferented $\mathrm{MVN}$ at D3 when compared to the UVN-NaCl group ( $p<0.001$; Figure $5 b, c)$. However, the number of proliferative cells $\left(\mathrm{BrdU}^{+}\right)$in the UVN-T4 group at D30 was similar to the UVN-NaCl group.

We then evaluated the cellular fate of the newly generated cells $\left(\mathrm{BrdU}^{+}\right)$with a single injection of BrdU $(200 \mathrm{mg} / \mathrm{kg})$ at D3 post-UVN, prior to intracardiac perfusion at D30 (Figure 5a). Cellular markers were revealed by double immunohistochemical labeling presented in Figure 5d. In the MVN of the UVN-NaCl group, it was possible to determine the presence of newly generated neurons $\left(\mathrm{BrdU}^{+} / \mathrm{NeuN}^{+}\right)$, astrocytes $\left(\mathrm{BrdU}^{+} / \mathrm{GFAP}^{+}\right)$, and microglia $\left(\mathrm{BrdU}^{+} / \mathrm{IBA}^{+}\right)$in almost equivalent proportion $(\sim 20 \%)$ with a predominance of the oligodendrocyte $\left(\mathrm{BrdU}^{+} / \mathrm{Olig}^{+}\right)$phenotype $(32 \%)$ (Figure $\left.5 \mathrm{e}\right)$. Based on the literature, $\mathrm{TH}$ promotes the engagement of neural stem cells preferentially towards a neural fate $[14,40,42,44]$. Surprisingly, with our paradigm, we observed an increased formation of new microglial cells ( 41 vs. $24 \%$ ) at the expense of new neurons ( 5 vs. $23 \%$ ) in UVN-T4 group when compared to UVN-NaCl, respectively (Figure 5f).

\subsection{L-Thyroxine Modulates the Glial Reaction and Prevents Downregulation of KCC2 in the Deafferented Vestibular Nuclei}

As reported in our previous studies, UVN induces a significant increase in microglia (IBA1), astrocytes (GFAP), and oligodendrocytes (Olig2) at D3 post-lesion in the deafferented vestibular nuclei [5-8,10] (Figure 6a-d). The number of microglial cells was reduced in the UVN-T4 group when compared to UVN-NaCl rats at D3 post-lesion $(p<0.001$; Figure $6 a, b)$. However, the number of microglial cells in the UVN-T4 group was still significantly increased when compared to pre-operative values $(p<0.001)$. No difference in the number of astrocytes was found between the UVN-NaCl and UVN-T4 groups (Figure 6a,c). Finally, the number of oligodendrocytes at D3 was reduced in the UVN-T4 group when compared to both the UVN-NaCl group $(p<0.001)$ and pre-operative values $(p<0.01$; Figure $6 a, d)$. At D30 post-lesion, the number of oligodendrocytes for the UVN-T4 group was comparable with the UVN-NaCl group (Figure 6a). 


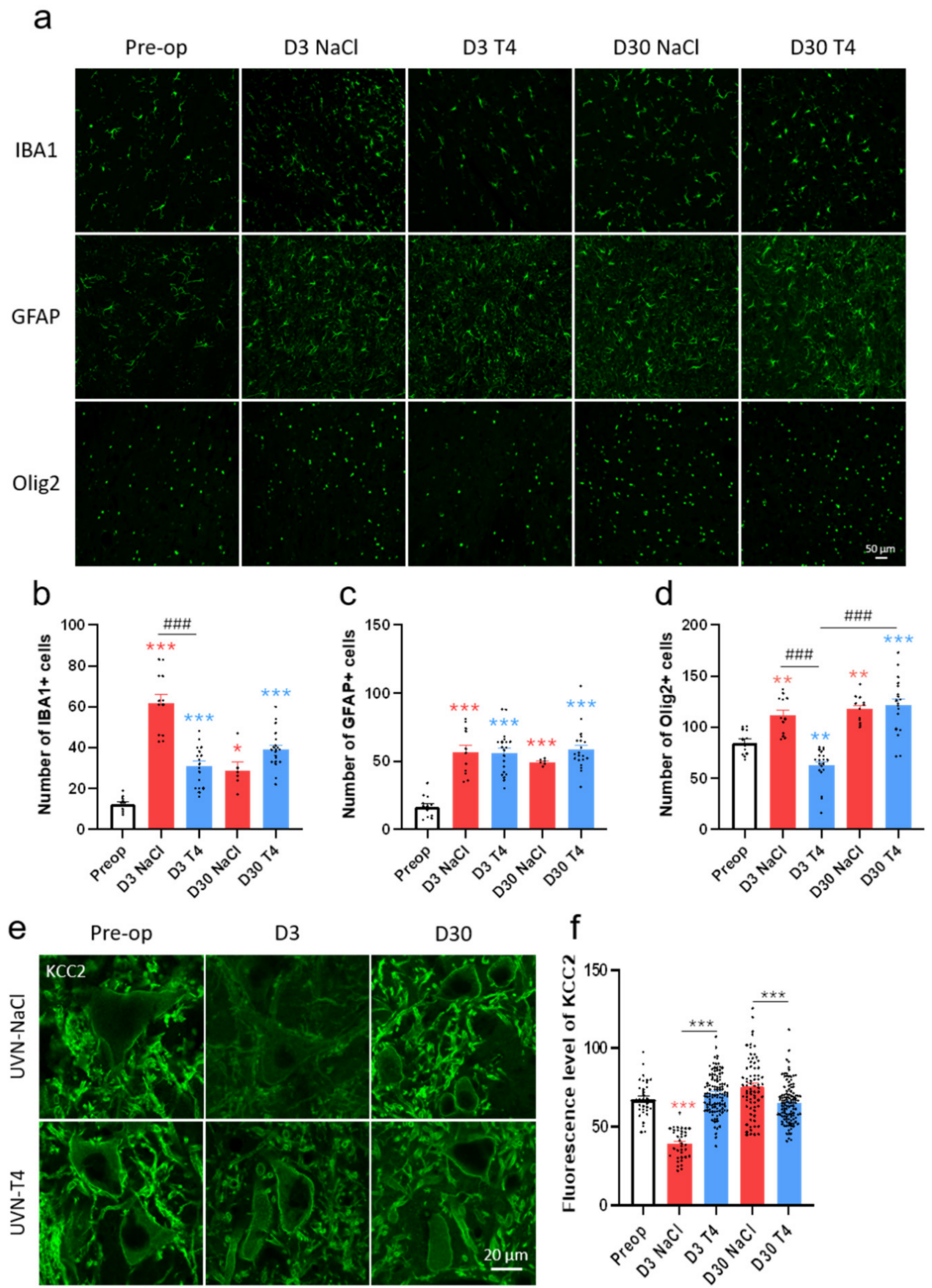

Figure 6. L-T4 treatment modulates glial reaction in the deafferented medial vestibular nucleus after UVN. (a) Confocal immunostaining images of $\mathrm{IBA}^{+}, \mathrm{GFAP}^{+}$, and Olig2 ${ }^{+}$cells in the deafferented medial vestibular nucleus (MVN) before the lesion (pre-op), three days (D3), and thirty days (D30) after unilateral vestibular neurectomy (UVN) for UVN-NaCl and UVN-T4 groups. Scale bar $=50 \mu \mathrm{m}$. (b-d) Quantitative assessment of the effect of UVN and L-T4 treatment on the number of IBA1 ${ }^{+}(\mathbf{b})$, $\mathrm{GFAP}^{+}(\mathbf{c})$, and Olig2 ${ }^{+}(\mathbf{d})$ cells in the deafferented MVN of UVN-NaCl (red, $n=4 /$ delay) and UVN-T4 (blue, $n=4$ /delay) groups. (e) Confocal immunostaining images in the deafferented lateral vestibular nucleus showing the KCC2 staining (green) in vestibular neurons of UVN-NaCl and UVN-T4 groups, observed prior to lesioning (pre-op, $n=4)$, D3 $(n=4)$ and D30 $(n=4)$ after UVN. (f) Quantification of the density of membrane labeling in vestibular neurons of intact rats and in $\mathrm{UVN}-\mathrm{NaCl}$ (red) and UVN-T4 (blue) groups at either D3 or D30 after UVN. Scale bar $=20 \mu \mathrm{m}$. Error bars represent SEM. A significant difference from the pre-operative value is indicated by * in red for UVN-NaCl group. A significant difference from the pre-operative value is indicated by * in blue for UVN-T4 group. A significant difference between $\mathrm{UVN}-\mathrm{NaCl}$ and UVN-T4 group is indicated with \# in black $\left({ }^{*} p<0.05\right.$, ${ }^{* *} p<0.01,{ }^{* * *} p<0.001$; One-way ANOVA and Tuckey's post hoc tests). 
We previously hypothesized that UVN-induced microglia upregulation triggered a microglia-BDNF-TrkB signaling pathway that decreased KCC2 expression in the deafferented vestibular nuclei [8]. This hypothesis of a downregulation of KCC2 by BDNF and microglia is supported by other studies [45-47]. As we showed a decrease in microglia with L-T4 injections at D3, we wondered if KCC2 expression was also altered. While UVN-NaCl animals had reduced KCC2 expression at D3 post-lesion when compared to pre-operative values $(p<0.001)$, no difference was found for the UVN-T4 group (Figure 6e,f). In addition, KCC2 expression in UVN-T4 rats at D3 post-UVN was increased when compared to $\mathrm{UVN}-\mathrm{NaCl}$ rats on the same day $(p<0.001)$. Restoration of KCC2 expression was achieved one month after the lesion for the UVN-NaCl group. However, we observed a significant increase in KCC2 expression for UVN-NaCl rats when compared to UVN-T4 rats 30 days after UVN ( $p<0.001$; Figure 6f).

3.7. L-T4-Treated Rats Exhibit Enhanced Metabolic Activity in the Vestibular Nuclei Three Days after UVN

It has been known for a century that $\mathrm{TH}$ regulates energy metabolism $[21,22,48]$. Quantification of cytochrome oxidase (CO)-labeled neurons can provide insight into the metabolic effect of L-T4 in the vestibular nuclei after UVN. We focused on the lateral vestibular nucleus (LVN) in view of the extensive vestibulo-spinal projections of this nucleus implicated in gait and balance [49,50], both at an acute (D3) and a compensated stage (D30) after UVN (summary of the study design presented in Figure 7a). The number of CO-labeled neurons in UVN-T4 group on both ipsi- and contralesional LVN is increased when compared to both sides of the LVN in the UVN-NaCl group at D3 post-lesion $(p<0.001$; Figure $7 \mathrm{~b}, \mathrm{c})$. One month after the lesion, both groups had a lower number of $\mathrm{CO}$-labeled neurons, but the number of CO-labeled neurons on the ipsilesional LVN in the UVN-T4 group had increased when compared to the same side of LVN in the UVN-NaCl group ( $p<0.05 ;$ Figure 7b,d). These data suggest that L-T4 injections enhanced metabolic activity in the LVN during the first days after the lesion, which is consistent with the behavioral results.

a

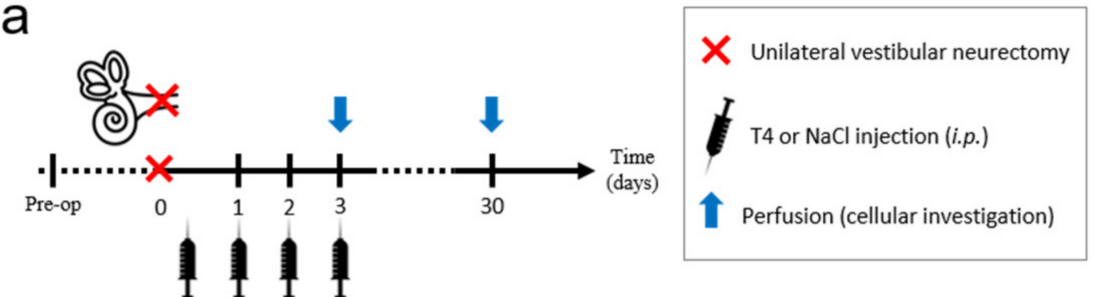

b

UVN-NaCl

UVN-T4

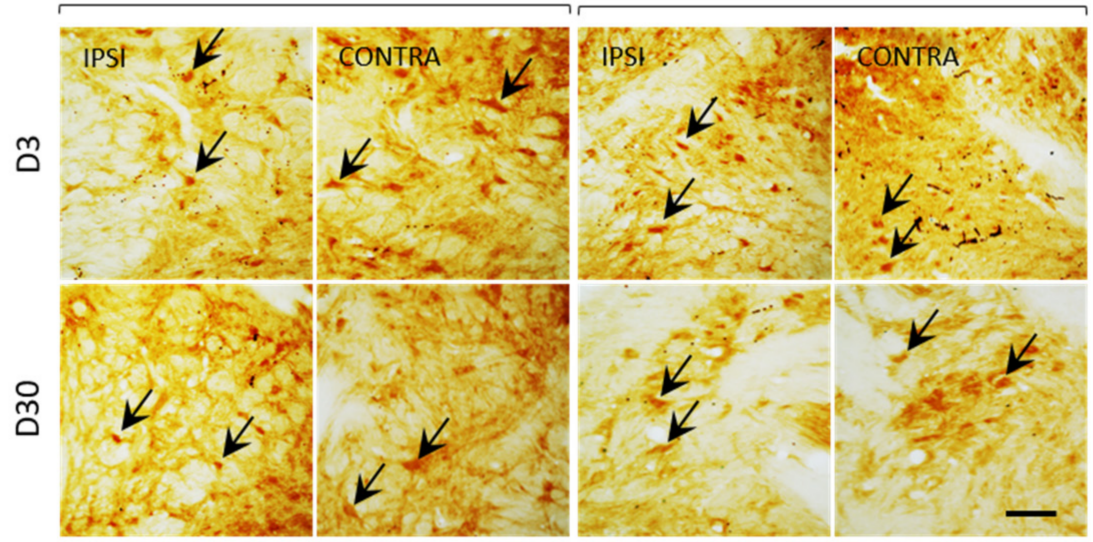

Figure 7. Cont. 

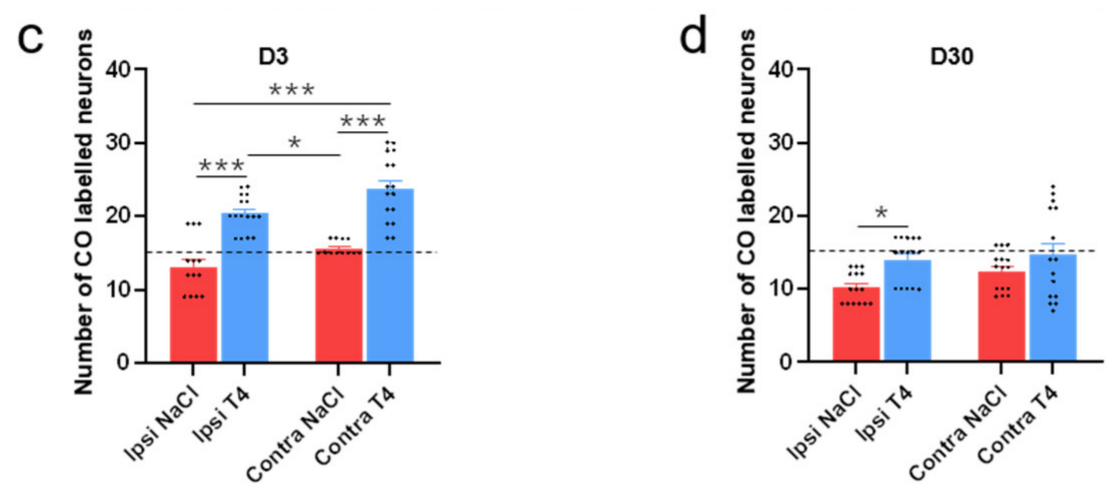

Figure 7. L-T4 treatment after UVN enhances metabolic activity in the vestibular nuclei. (a) Study design used to assess cellular consequences of acute L-thyroxine (L-T4) treatment after unilateral vestibular neurectomy (UVN). UVN-T4 group received L-T4 injections (10 $\mu \mathrm{g} / \mathrm{kg}$, i.p.) and UVN$\mathrm{NaCl}$ group received $0.9 \% \mathrm{NaCl}$ (vehicle, in equivalent volume, i.p.) at the end of the UVN and one injection/day during the first 3 days post-lesion. Animals were perfused either at an acute stage of vestibular compensation ( $3 \mathrm{~h}$ after the BrdU injection on day 3 ) or at a compensated stage (on day 30). (b) Illustrations of cytochrome oxidase (CO) enzymatic labeling in the lateral vestibular nucleus (LVN) of the UVN-NaCl $(n=4$ /delay) and UVN-T4 $(n=4$ /delay) groups observed at three days (D3) and thirty days (D30) after unilateral vestibular neurectomy (UVN). Illustrations are shown on both the contralesional and ipsilesional (deafferented) side. (c-d) Quantitative assessment of the effect of UVN and L-T4 treatment on the number of CO-labeled neurons in the LVN at D3 (c) or D30 (d). Dashed line represents the pre-operative value of the number of CO-labeled neurons in the LVN. Error bars represent SEM. A significant difference between $\mathrm{UVN}-\mathrm{NaCl}$ and $\mathrm{UVN}-\mathrm{T} 4$ group is indicated with * in black ( ${ }^{*} p<0.05,{ }^{* * *} p<0.001$; one-way ANOVA and Tuckey's post hoc tests). Black arrows indicate example of $\mathrm{CO}^{+}$neurons. Scale bar $=25 \mu \mathrm{m}$.

\section{Discussion}

The effect of a short-term L-T4 treatment on the vestibular syndrome following UVN struck: all the vestibular behavioral parameters we analyzed, showing a significant improvement. Our qualitative assessment of the vestibular syndrome indicated about 30\% reduction in symptoms in the UVN-T4 group at the first day after the lesion. In addition, L-T4-treated animals reached the plateau of vestibular compensation earlier than untreated animals (between 3 and 7 days vs. 10 days). Based on our previous work [28,29,33], we analyzed more specifically the posturo-locomotor syndrome and demonstrated that LT4 treatment promoted a faster recovery of postural and locomotor functions that had been impaired by UVN. The reported improvements in walking speed and acceleration in L-T4-treated rats can be directly transposed to the clinic. Increasing walking speed for vestibular patients is considered as an improvement during a vestibular rehabilitation program [51-53]. Furthermore, changes in gait speed and accelerations can be used to assess dynamic postural stability (e.g., by Dynamic Gait Index) [54], and can be used in vestibulospinal exercises for vestibular rehabilitation $[53,55,56]$. The future clinical implications of the beneficial effect of $\mathrm{TH}$ on vestibular compensation for therapy of patients with acute vestibular loss can be two-fold: (1) Similarly to the current rat experiments, L-T4 could be administered in the acute phase of vestibular syndrome to reduce symptoms of vestibular asymmetry and accelerate vestibular compensation. The translation to clinical practice is facilitated by the widespread availability of L-T4 medication; (2) pre-existing hypothyroidism may be considered as a risk factor for poor vestibular compensation or vertigo, which should be screened more regularly [57-60].

The TH is represented by T3 and T4 molecules; moreover, the principal product of the thyroid gland is T4, which is converted into T3 by the DIO2 enzyme. The genomic effects of TH are mediated by the ability of TH nuclear receptors $(\mathrm{TR} \alpha$ and $\mathrm{TR} \beta)$ to interact directly with gene promoters in the presence or absence of their ligand, which is primarily T3. In the present study, we observed short (from D1 to D3) but also long-term effects 
(at D30). Although a short-term effect is unlikely for a hormone that acts by regulating gene expression, the obtained results support a more rapid mode of action of TH. Over the past years, many different studies have illustrated the possibility of a rapid response and several alternative, so-called non-genomic pathways for TH action (for review see: [21,61]). Indeed, TH could participate in signaling pathways independently of direct or indirect DNA binding or can act independently of the TH receptor [35] through the integrin $\alpha \mathrm{V} \beta 3$ receptor [62]. Despite the fascinating physiological effect of L-T4 on vestibular function recovery in UVN rats, the intimate mechanisms by which thyroid hormones act remain to be elucidated, but we can hypothesize the different pathways involved.

The different symptoms observed after unilateral vestibular loss result from asymmetry of spontaneous electrical activity between homologous VN [63,64]. The data in the literature show that the restoration of electrophysiological equilibrium between the two opposite $\mathrm{VN}$ is the key parameter for the functional recovery of postural, locomotor, and gaze stabilization functions $[2,65,66]$. TH is known to stimulate diverse metabolic activities, resulting in increased ATP and oxygen consumption $[22,67,68]$. In line with the literature, the L-T4-treated group exhibited a bilateral increase in the number of CO-labeled neurons in the LVN three days after UVN when compared to the UVN-NaCl group. Moreover, the increased number of CO-labeled neurons observed in the deafferented LVN in the UVN-T4 group was significantly higher than that observed in the contralesional LVN of the vehicle-treated group, highlighting a drastic increase in metabolic activity due to L-T4 treatment. In relation to the increase in metabolic activity of neurons, T3 and T4 administration reduced GABA-evoked current and modulate inhibitory neurotransmission by non-genomics mechanisms [69,70]. Thus, stimulation of metabolic activity and inhibition of GABAergic neurotransmission by L-T4 treatment could increase the excitability of ipsilesional vestibular neurons, thereby reducing the electrophysiological asymmetry between homologous vestibular nuclei, which attenuates the syndrome and accelerates vestibular compensation. Furthermore, the fact that we observed an increase in the expression of $\mathrm{CO}$ on the healthy side can be explained by an action of L-T4 on local inhibitory or commissural excitatory neurons (with projection towards the injured side). This action of L-T4 on the intact side would also participate in the rebalancing of activity between homologous VN. The architecture of the vestibular neural networks has already been well explained in a previous article [4].

Interestingly, the deafferented vestibular environment has been reconfigured to ensure the binding of endogenous and exogenous thyroid hormones by increasing TR $\alpha$ expression in the UVN-T4 group. As DIO2 enzyme is mainly expressed in astrocytes [37], we can hypothesize that the astroglial reaction observed in UVN animals actively participates in the conversion of T4 in T3 and supports all the mechanisms promoting vestibular compensation in response to the metabolic energy demand of the deafferented VN. Indeed, a proteomic analysis in the MVN of rats one week after unilateral labyrinthectomy (UL) showed an increase in proteins associated with mitochondrial function and energy metabolism [71]. One of these proteins was succinate dehydrogenase, a crucial enzyme in the mitochondrial Krebs cycle, for which positive regulation was observed at 5 and 15 days after UVN in the ipsilesional LVN of rabbits [72]. Overall, these changes reflect the high metabolic energy demand of the deafferented VN, which is associated with glial response, cell proliferation, neurogenesis, and structural remodeling to compensate for the loss of vestibular input.

Based on other studies [45-47], we have proposed that UVN-induced upregulation of microglia triggers a microglia-BDNF-TrkB signaling pathway that transiently decreases KCC2 expression in the deafferented VN of the feline model [8]. We postulated that this acute and transient KCC2 remodeling promotes a depolarizing action of GABA, facilitating the restoration of the excitability level in the deafferented vestibular environment that is crucial for vestibular function recovery. In the present study, we reproduced this result on the UVN rodent model, but we demonstrated that L-T4 treatment prevents the negative regulation of KCC2 in the deafferented LVN when compared to the UVN-NaCl group. A first explanatory hypothesis is that recourse to this transient KCC2 downregulation, with a 
view to restoring the excitability of deafferented VN, is no longer necessary. Indeed, the energy metabolism increased by $\mathrm{T} 4$ treatment can probably alone support the restoration of the level of excitability, underlying a faster functional restoration. However, an opposite action of BDNF on KCC2 expression has been described in axotomized corticospinal neurons [73]. Whereas in intact mature neurons BDNF downregulates KCC2 [47,74,75], in injured neurons, BDNF upregulates KCC2 [8,73,74]. Interestingly, TH have been shown to increase the expression of BDNF in lesioned slices of the hippocampus $[18,76]$ and other pathological models [15-17]. We can then assume that a short-term L-T4 treatment after UVN induces a local increase of BDNF in the deafferented VN, thus blocking KCC2 downregulation and promoting cell proliferation as demonstrated in our previous study in the UVN feline model [8]. Finally, the absence of KCC2 downregulation induced after L-T4 treatment is consistent with the hypothesis of Kaila et al. [32], which proposes that "downregulation of KCC2 following neuronal trauma may be part of a general adaptive cellular response that facilitates neuronal survival by reducing the energetic costs that are needed to preserve low $\left[\mathrm{Cl}^{-}\right]_{i}$ ". By providing $\mathrm{TH}$, known to increase energy metabolism, the internalization of KCC2 to reduce energy costs after UVN would no longer be necessary.

Unsurprisingly, L-T4 injections after UVN reduce the number of Olig2 ${ }^{+}$cells and prevent the increase of SOX $2^{+}$cells in the deafferented VN. These results are congruent with the literature [40,77], and are in agreement with the increased cell proliferation observed in the UVN-T4 group three days after the lesion. However, in our paradigm we did not observe cell differentiation preferentially towards a neuronal fate (BrdU ${ }^{+} / \mathrm{NeuN}^{+}$cells) with the L-T4 treatment. On the contrary, cell differentiation was promoted towards a microglial cell phenotype $\left(\mathrm{Brdu}^{+} / \mathrm{IBA}^{+}\right.$cells) in the UVN-T4 group. This result could appear paradoxical, since TH promotes the engagement of neural stem cells preferentially towards a neuronal fate $[14,40,42,44]$. Yet, our results do not contradict this well-established concept. As expected, L-T4 injections during the first three days post-UVN significantly increased cell proliferation on the third day without impacting the cell survival ratio. It is noteworthy that cell differentiation and survival in the present study were evaluated at day 30, which is 4 weeks after the last L-T4 injection. Given the T4 half-life of 12-24 h in rats [78], the treatment during the first 3 days after UVN had been eliminated from the system when cell differentiation and survival was assessed (at D30 after UVN). We believe that an extended treatment window would have revealed an increased cell survival and neural differentiation as described in the literature. Another explanation could come from the reduction of the vestibular syndrome observed with L-T4 treatment in the first days after injury. Neurogenesis is indeed expressed in the UVN model, but not in the labyrinthine lesion or hair cell destruction model [6]. What differentiates these three models is the severity of the vestibular syndrome; it is most severe in the UVN model and weaker in the other two models. Since the UVN-vestibular syndrome is considerably reduced by L-T4 treatment and the vestibular compensation is accelerated (more akin to the kinetics of a labyrinthine lesion model), it is possible that neuronal differentiation is not necessary to compensate for the deficits. In agreement with this hypothesis, we have demonstrated a decrease in the percentage of $\mathrm{BrdU}^{+} / \mathrm{NeuN}^{+}$in cats treated with BDNF, showing an improvement in vestibular compensation [8]. With this hormonal treatment, we provide other compensation pathways to the central nervous system, notably based on energy metabolism and excitability, which could explain the limited number of newly generated neurons we observed in our model.

We demonstrated, in this study, that L-T4 treatment promotes microglial rather than neuronal differentiation. It is interesting to mention that the same result was recently observed in the same UVN rodent model subjected to a sensorimotor rehabilitation protocol [79]. Likewise, T3 increases the number of microglia cell bodies, promotes microglia survival, and enhances the growth of their processes [80]. Like neurogenesis, microglia also appears as a factor interacting with different plasticity mechanisms of the deafferented vestibular environment (excitability, inflammation, neuroprotection, etc.) promoting vestibular function recovery [79]. 
Obviously, the results obtained support a local action of TH in the deafferented VN. However, given the intraperitoneal administration, we cannot exclude an effect on the whole central network of vestibular compensation [81,82] as well as peripheral effects. Skeletal muscle is in fact a primary target for TH signaling in human and rodents [83]. TH are involved in contractile function by increasing the rate of muscle relaxation-contraction, in energy metabolism by increasing mitochondrial biogenesis, but also in myogenesis and muscle regeneration $[83,84]$. Interestingly, UVN induces asymmetry of muscle tone with ipsilesional hypotonia and contralesional hypertonia [24,85], thus altering the postural and locomotor balancing function. While no studies to date have demonstrated an increase in muscle tone after TH administration, it is plausible to hypothesize that by increasing contractile function and muscle metabolism, L-T4 treatment could accelerate the rebalancing of muscle tone after UVN, which is crucial for postural stability.

In summary, short-term administration of L-T4 after unilateral vestibular loss greatly reduces vestibular syndrome and improves vestibular compensation. The present results demonstrate different mechanisms of action of L-T4 underlying the antivertigo effect and open new perspectives of L-T4 treatment for acute vestibular loss.

\section{Clinical Relevance}

The UVN model consists of a complete surgical section of the vestibular nerve unilaterally $[24,86]$. It therefore first produces the neurophysiological conditions encountered in vestibular neurotomy $[87,88]$. It can be anticipated that the antivertigo effect revealed in the present study may benefit patients undergoing this type of intervention. Further pre-clinical studies in the UVN rodent model should help define the most appropriate dosage and administration window before proceeding to clinical trials.

The etiological mechanisms leading to peripheral vestibulopathies are not fully established so far. However, at least some of these conditions may result from partial deafferentation of peripheral vestibular sensors unilaterally. Although it is currently unknown to what extent these peripheral damage impacts the central vestibular networks. It could be interesting to test the effect of L-T4 on the different types of vestibular deafferentation models available in rodents [86,89-91], to evaluate its possible use in human pathologies such as acute peripheral vestibulopathy, or Ménière's disease. Also, other pharmacological compounds mimicking or modulating the effect of L-T4 should be tested in order to identify potential drug candidates to relieve peripheral vestibulopathies.

Supplementary Materials: The following supporting information can be downloaded at: https: / / www.mdpi.com/article/10.3390/cells11040684/s1, Video S1: rat injected with saline solution one day after UVN, Video S2: rat injected with T4 treatment one day after UVN.

Author Contributions: G.R. and B.T. conceived the study. G.R. performed behavioral pharmacology. G.R., I.W. and A.L. performed immunohistochemical experiments. D.P. developed and performed the surgeries. A.T. provided expertise and contributed to confocal microscopy. G.R., E.M., N.E.-M., A.L.-J., A.E.-A., C.C. and B.T. contributed to data analysis and interpretation of the results. P.C., M.-J.E.F. and A.Z. provided medical expertise. G.R. and B.T. wrote the manuscript, and all authors contributed to its editing. All authors have read and agreed to the published version of the manuscript.

Funding: This research was funded by grants from the Ministère de l'Enseignement Supérieur et de la Recherche and CNRS (Aix-Marseille Université, UMR 7291). This work has received support from the French government under the Programme Investissements d'Avenir, Initiative d'Excellence d'Aix-Marseille Université via A*Midex (AMX-19-IET-004) and ANR (ANR-17-EURE-0029) funding.

Institutional Review Board Statement: The animal study protocol used for this study were in accordance with the European directive (2010/63/CE). The project protocols were approved by the Ethics Committee ${ }^{\circ} 71$ registered at the National Committee for Ethical Reflection on Animal Experimentation and by the Ministère de l'Enseignement Supérieur et de la Recherche under the reference number APAFIS\# 11403-2018092510586508.

Informed Consent Statement: Not applicable. 
Data Availability Statement: The data presented in this study are available on request from the corresponding author.

Acknowledgments: We thank Elodie Mansour and Jean Luc Fina for taking care of the animals. We thank Justine Facchini and Jacques Leonard for their help with the figures and videos and Michael Paul for proofreading the English text.

Conflicts of Interest: The authors declare no conflict of interest.

\section{References}

1. Curthoys, I.S. Vestibular Compensation and Substitution. Curr. Opin. Neurol. 2000, 13, 27. [CrossRef] [PubMed]

2. Dutia, M.B. Mechanisms of Vestibular Compensation: Recent Advances. Curr. Opin. Otolaryngol. Head Neck Surg. 2010, 18, 420-424. [CrossRef] [PubMed]

3. Lacour, M.; Tighilet, B. Plastic Events in the Vestibular Nuclei during Vestibular Compensation: The Brain Orchestration of a "Deafferentation" Code. Restor. Neurol. Neurosci. 2010, 28, 19-35. [CrossRef] [PubMed]

4. Tighilet, B.; Leonard, J.; Mourre, C.; Chabbert, C. Apamin Treatment Accelerates Equilibrium Recovery and Gaze Stabilization in Unilateral Vestibular Neurectomized Cats: Cellular and Behavioral Aspects. Neuropharmacology 2019, 144, 133-142. [CrossRef]

5. Dutheil, S.; Brezun, J.M.; Leonard, J.; Lacour, M.; Tighilet, B. Neurogenesis and Astrogenesis Contribution to Recovery of Vestibular Functions in the Adult Cat Following Unilateral Vestibular Neurectomy: Cellular and Behavioral Evidence. Neuroscience 2009, 164, 1444-1456. [CrossRef]

6. Dutheil, S.; Lacour, M.; Tighilet, B. Neurogenic Potential of the Vestibular Nuclei and Behavioural Recovery Time Course in the Adult Cat Are Governed by the Nature of the Vestibular Damage. PLoS ONE 2011, 6, e22262. [CrossRef]

7. Dutheil, S.; Escoffier, G.; Gharbi, A.; Watabe, I.; Tighilet, B. GABAA Receptor Agonist and Antagonist Alter Vestibular Compensation and Different Steps of Reactive Neurogenesis in Deafferented Vestibular Nuclei of Adult Cats. J. Neurosci. 2013, 33, 15555-15566. [CrossRef]

8. Dutheil, S.; Watabe, I.; Sadlaoud, K.; Tonetto, A.; Tighilet, B. BDNF Signaling Promotes Vestibular Compensation by Increasing Neurogenesis and Remodeling the Expression of Potassium-Chloride Cotransporter KCC2 and GABAA Receptor in the Vestibular Nuclei. J. Neurosci. 2016, 36, 6199-6212. [CrossRef]

9. Tighilet, B.; Brezun, J.M.; Dit Duflo Sylvie, G.; Gaubert, C.; Lacour, M. New Neurons in the Vestibular Nuclei Complex after Unilateral Vestibular Neurectomy in the Adult Cat: Reactive Neurogenesis in Adult Vestibular Lesioned Cats. Eur. J. Neurosci. 2007, 25, 47-58. [CrossRef]

10. Rastoldo, G.; El Mahmoudi, N.; Marouane, E.; Pericat, D.; Watabe, I.; Toneto, A.; López-Juárez, A.; Chabbert, C.; Tighilet, B. Adult and Endemic Neurogenesis in the Vestibular Nuclei after Unilateral Vestibular Neurectomy. Prog. Neurobiol. 2021, 196, 101899. [CrossRef]

11. Fanibunda, S.E.; Desouza, L.A.; Kapoor, R.; Vaidya, R.A.; Vaidya, V.A. Thyroid Hormone Regulation of Adult Neurogenesis. In Vitamins and Hormones; Elsevier: Amsterdam, The Netherlands, 2018; Volume 106, pp. 211-251. ISBN 978-0-12-814116-8.

12. Gothié, J.-D.; Demeneix, B.; Remaud, S. Comparative Approaches to Understanding Thyroid Hormone Regulation of Neurogenesis. Mol. Cell. Endocrinol. 2017, 459, 104-115. [CrossRef] [PubMed]

13. Kapoor, R.; Fanibunda, S.E.; Desouza, L.A.; Guha, S.K.; Vaidya, V.A. Perspectives on Thyroid Hormone Action in Adult Neurogenesis. J. Neurochem. 2015, 133, 599-616. [CrossRef] [PubMed]

14. Remaud, S.; Gothié, J.-D.; Morvan-Dubois, G.; Demeneix, B.A. Thyroid Hormone Signaling and Adult Neurogenesis in Mammals. Front. Endocrinol. 2014, 5, 62. [CrossRef] [PubMed]

15. Genovese, T.; Impellizzeri, D.; Ahmad, A.; Cornelius, C.; Campolo, M.; Cuzzocrea, S.; Esposito, E. Post-Ischaemic Thyroid Hormone Treatment in a Rat Model of Acute Stroke. Brain Res. 2013, 1513, 92-102. [CrossRef]

16. Mokhtari, T.; Akbari, M.; Malek, F.; Kashani, I.R.; Rastegar, T.; Noorbakhsh, F.; Ghazi-Khansari, M.; Attari, F.; Hassanzadeh, G. Improvement of Memory and Learning by Intracerebroventricular Microinjection of T3 in Rat Model of Ischemic Brain Stroke Mediated by Upregulation of BDNF and GDNF in CA1 Hippocampal Region. DARU J. Pharm. Sci. 2017, 25, 1-11. [CrossRef]

17. Bavarsad, K.; Hadjzadeh, M.-A.-R.; Hosseini, M.; Pakdel, R.; Beheshti, F.; Bafadam, S.; Ashaari, Z. Effects of Levothyroxine on Learning and Memory Deficits in a Rat Model of Alzheimer's Disease: The Role of BDNF and Oxidative Stress. Drug Chem. Toxicol. 2018, 43, 57-63. [CrossRef]

18. Shulga, A.; Blaesse, A.; Kysenius, K.; Huttunen, H.J.; Tanhuanpää, K.; Saarma, M.; Rivera, C. Thyroxin Regulates BDNF Expression to Promote Survival of Injured Neurons. Mol. Cell. Neurosci. 2009, 42, 408-418. [CrossRef]

19. Liu, Y.-Y.; Brent, G.A. The Role of Thyroid Hormone in Neuronal Protection. Compr. Physiol. 2021, 11, 2075-2095. [CrossRef]

20. Talhada, D.; Santos, C.R.A.; Gonçalves, I.; Ruscher, K. Thyroid Hormones in the Brain and Their Impact in Recovery Mechanisms After Stroke. Front. Neurol. 2019, 10, 1103. [CrossRef]

21. Cheng, S.-Y.; Leonard, J.L.; Davis, P.J. Molecular Aspects of Thyroid Hormone Actions. Endocr. Rev. 2010, 31, 139-170. [CrossRef]

22. Mullur, R.; Liu, Y.-Y.; Brent, G.A. Thyroid Hormone Regulation of Metabolism. Physiol. Rev. 2014, 94, 355-382. [CrossRef] [PubMed]

23. Vaitkus, J.A.; Farrar, J.S.; Celi, F.S. Thyroid Hormone Mediated Modulation of Energy Expenditure. Int. J. Mol. Sci. 2015, 16, 16158-16175. [CrossRef] [PubMed] 
24. Péricat, D.; Farina, A.; Agavnian-Couquiaud, E.; Chabbert, C.; Tighilet, B. Complete and Irreversible Unilateral Vestibular Loss: A Novel Rat Model of Vestibular Pathology. J. Neurosci. Methods 2017, 283, 83-91. [CrossRef]

25. Boadas-Vaello, P.; Riera, J.; Llorens, J. Behavioral and Pathological Effects in the Rat Define Two Groups of Neurotoxic Nitriles. Toxicol. Sci. Off. J. Soc. Toxicol. 2005, 88, 456-466. [CrossRef] [PubMed]

26. Hardisty-Hughes, R.E.; Parker, A.; Brown, S.D.M. A Hearing and Vestibular Phenotyping Pipeline to Identify Mouse Mutants with Hearing Impairment. Nat. Protoc. 2010, 5, 177-190. [CrossRef]

27. Liberge, M.; Manrique, C.; Bernard-Demanze, L.; Lacour, M. Changes in TNFa, NF B and MnSOD Protein in the Vestibular Nuclei after Unilateral Vestibular Deafferentation. J. Neroinflamm. 2010, 7, 91. [CrossRef]

28. Tighilet, B.; Péricat, D.; Frelat, A.; Cazals, Y.; Rastoldo, G.; Boyer, F.; Dumas, O.; Chabbert, C. Adjustment of the Dynamic Weight Distribution as a Sensitive Parameter for Diagnosis of Postural Alteration in a Rodent Model of Vestibular Deficit. PLoS ONE 2017, 12, e0187472. [CrossRef]

29. Rastoldo, G.; Marouane, E.; El Mahmoudi, N.; Péricat, D.; Bourdet, A.; Timon-David, E.; Dumas, O.; Chabbert, C.; Tighilet, B. Quantitative Evaluation of a New Posturo-Locomotor Phenotype in a Rodent Model of Acute Unilateral Vestibulopathy. Front. Neurol. 2020, 11, 505. [CrossRef]

30. Paxinos, G.; Watson, C. The Rat Brain in Stereotaxic Coordinates, 7th ed.; Academic Press: Cambridge, MA, USA, 2013; ISBN 978-0-12-391949-6.

31. Tighilet, B.; Dutheil, S.; Siponen, M.I.; Noreña, A.J. Reactive Neurogenesis and Down-Regulation of the Potassium-Chloride Cotransporter KCC2 in the Cochlear Nuclei after Cochlear Deafferentation. Front. Pharmacol. 2016, 7. [CrossRef]

32. Kaila, K.; Price, T.J.; Payne, J.A.; Puskarjov, M.; Voipio, J. Cation-Chloride Cotransporters in Neuronal Development, Plasticity and Disease. Nat. Rev. Neurosci. 2014, 15, 637-654. [CrossRef]

33. Marouane, E.; Rastoldo, G.; El Mahmoudi, N.; Péricat, D.; Chabbert, C.; Artzner, V.; Tighilet, B. Identification of New Biomarkers of Posturo-Locomotor Instability in a Rodent Model of Vestibular Pathology. Front. Neurol. 2020, 11, 470. [CrossRef]

34. Tighilet, B.; Léonard, J.; Watabe, I.; Bernard-Demanze, L.; Lacour, M. Betahistine Treatment in a Cat Model of Vestibular Pathology: Pharmacokinetic and Pharmacodynamic Approaches. Front. Neurol. 2018, 9, 431. [CrossRef] [PubMed]

35. Flamant, F.; Cheng, S.-Y.; Hollenberg, A.N.; Moeller, L.C.; Samarut, J.; Wondisford, F.E.; Yen, P.M.; Refetoff, S. Thyroid Hormone Signaling Pathways: Time for a More Precise Nomenclature. Endocrinology 2017, 158, 2052-2057. [CrossRef] [PubMed]

36. Bianco, A.C.; Kim, B.W. Deiodinases: Implications of the Local Control of Thyroid Hormone Action. J. Clin. Investig. 2006, 116, 2571-2579. [CrossRef] [PubMed]

37. Guadano-Ferraz, A.; Obregon, M.J.; Germain, D.L.S.; Bernal, J. The Type 2 Iodothyronine Deiodinase Is Expressed Primarily in Glial Cells in the Neonatal Rat Brain. Proc. Natl. Acad. Sci. USA 1997, 94, 10391-10396. [CrossRef] [PubMed]

38. Liu, Y.-Y.; Brent, G.A. Thyroid Hormone and the Brain: Mechanisms of Action in Development and Role in Protection and Promotion of Recovery after Brain Injury. Pharmacol. Ther. 2018, 186, 176-185. [CrossRef]

39. Mohácsik, P.; Zeöld, A.; Bianco, A.C.; Gereben, B. Thyroid Hormone and the Neuroglia: Both Source and Target. J. Thyroid Res. 2011, 2011, 1-16. [CrossRef]

40. López-Juárez, A.; Remaud, S.; Hassani, Z.; Jolivet, P.; Pierre Simons, J.; Sontag, T.; Yoshikawa, K.; Price, J.; Morvan-Dubois, G.; Demeneix, B.A. Thyroid Hormone Signaling Acts as a Neurogenic Switch by Repressing Sox2 in the Adult Neural Stem Cell Niche. Cell Stem Cell 2012, 10, 531-543. [CrossRef]

41. Li, H.; Godfrey, D.A.; Rubin, A.M. Astrocyte Reaction in the Rat Vestibular Nuclei after Unilateral Removal of Scarpa's Ganglion. Ann. Otol. Rhinol. Laryngol. 1999, 108, 181-188. [CrossRef]

42. Remaud, S.; Ortiz, F.C.; Perret-Jeanneret, M.; Aigrot, M.-S.; Gothié, J.-D.; Fekete, C.; Kvárta-Papp, Z.; Gereben, B.; Langui, D.; Lubetzki, C.; et al. Transient Hypothyroidism Favors Oligodendrocyte Generation Providing Functional Remyelination in the Adult Mouse Brain. eLife 2017, 6, e29996. [CrossRef]

43. Hartley, M.D.; Banerji, T.; Tagge, I.J.; Kirkemo, L.L.; Chaudhary, P.; Calkins, E.; Galipeau, D.; Shokat, M.D.; DeBell, M.J.; Van Leuven, S.; et al. Myelin Repair Stimulated by CNS-Selective Thyroid Hormone Action. JCI Insight 2019, 4, e126329. [CrossRef] [PubMed]

44. Gothié, J.D.; Sébillot, A.; Luongo, C.; Legendre, M.; Nguyen Van, C.; Le Blay, K.; Perret-Jeanneret, M.; Remaud, S.; Demeneix, B.A. Adult Neural Stem Cell Fate Is Determined by Thyroid Hormone Activation of Mitochondrial Metabolism. Mol. Metab. 2017, 6, 1551-1561. [CrossRef] [PubMed]

45. Coull, J.A.M.; Beggs, S.; Boudreau, D.; Boivin, D.; Tsuda, M.; Inoue, K.; Gravel, C.; Salter, M.W.; De Koninck, Y. BDNF from Microglia Causes the Shift in Neuronal Anion Gradient Underlying Neuropathic Pain. Nature 2005, 438, 1017-1021. [CrossRef] [PubMed]

46. Ferrini, F.; De Koninck, Y. Microglia Control Neuronal Network Excitability via BDNF Signalling. Neural Plast. 2013, $2013,1-11$ [CrossRef] [PubMed]

47. Rivera, C.; Li, H.; Thomas-Crusells, J.; Lahtinen, H.; Viitanen, T.; Nanobashvili, A.; Kokaia, Z.; Airaksinen, M.S.; Voipio, J.; Kaila, K.; et al. BDNF-Induced TrkB Activation down-Regulates the $\mathrm{K}+-\mathrm{Cl}-$ Cotransporter KCC2 and Impairs Neuronal Cl-Extrusion. J. Cell Biol. 2002, 159, 747-752. [CrossRef]

48. Wrutniak-Cabello, C.; Casas, F.; Cabello, G. Thyroid Hormone Action in Mitochondria. J. Mol. Endocrinol. 2001, 26 , 67-77. [CrossRef] 
49. McCall, A.A.; Miller, D.M.; Yates, B.J. Descending Influences on Vestibulospinal and Vestibulosympathetic Reflexes. Front. Neurol. 2017, 8, 112. [CrossRef]

50. Murray, A.J.; Croce, K.; Belton, T.; Akay, T.; Jessell, T.M. Balance Control Mediated by Vestibular Circuits Directing Limb Extension or Antagonist Muscle Co-Activation. Cell Rep. 2018, 22, 1325-1338. [CrossRef]

51. Alsalaheen, B.A.; Mucha, A.; Morris, L.O.; Whitney, S.L.; Furman, J.M.; Camiolo-Reddy, C.E.; Collins, M.W.; Lovell, M.R.; Sparto, P.J. Vestibular Rehabilitation for Dizziness and Balance Disorders after Concussion. J. Neurol. Phys. Ther. JNPT 2010, 34, 87-93. [CrossRef]

52. Meldrum, D.; Herdman, S.; Vance, R.; Murray, D.; Malone, K.; Duffy, D.; Glennon, A.; McConn-Walsh, R. Effectiveness of Conventional Versus Virtual Reality-Based Balance Exercises in Vestibular Rehabilitation for Unilateral Peripheral Vestibular Loss: Results of a Randomized Controlled Trial. Arch. Phys. Med. Rehabil. 2015, 96, 1319-1328. [CrossRef]

53. Verdecchia, D.H.; Monzón, A.M.; Urbina Jaimes, V.; Oliveira, F.R.; Paiva, L.d.S.; de Carvalho, T.D. Patient-Reported and Performance Outcomes Significantly Improved in Elderly Patients with Vestibular Impairment Following Rehabilitation: A Retrospective Study. J. Aging Res. 2018, 2018, 5093501. [CrossRef] [PubMed]

54. Wrisley, D.M.; Walker, M.L.; Echternach, J.L.; Strasnick, B. Reliability of the Dynamic Gait Index in People with Vestibular Disorders. Arch. Phys. Med. Rehabil. 2003, 84, 1528-1533. [CrossRef]

55. Kristiansen, L.; Magnussen, L.H.; Wilhelmsen, K.T.; Mæland, S.; Nordahl, S.H.G.; Clendaniel, R.; Hovland, A.; Juul-Kristensen, B. Efficacy of Intergrating Vestibular Rehabilitation and Cognitive Behaviour Therapy in Persons with Persistent Dizziness in Primary Care- a Study Protocol for a Randomised Controlled Trial. Trials 2019, 20, 575. [CrossRef] [PubMed]

56. Whitney, S.L.; Alghwiri, A.A.; Alghadir, A. An Overview of Vestibular Rehabilitation. Handb. Clin. Neurol. 2016, 137, 187-205. [CrossRef]

57. Hwang, G.; Saadi, R.; Patel, V.A.; Liaw, J.; Isildak, H. Thyroid Dysfunction in Ménière's Disease: A Comprehensive Review. ORL J. Oto-Rhino-Laryngol. Its Relat. Spec. 2021, 83, 219-226. [CrossRef] [PubMed]

58. Lin, W.-L.; Chen, C.-Y.; Hsu, T.-Y.; Chen, W.-K.; Lin, C.-L.; Chen, H.-C. Hypothyroidism Is an Independent Risk Factor for Menière's Disease: A Population-Based Cohort Study. Medicine 2019, 98, e15166. [CrossRef]

59. Miśkiewicz-Orczyk, K.A.; Lisowska, G.; Kajdaniuk, D.; Wojtulek, M. Can Hashimoto's Thyroiditis Cause Vertigo? Endokrynol. Pol. 2020, 70, 76-86. [CrossRef]

60. Santosh, U.P.; Rao, M.S.S. Incidence of Hypothyroidism in Meniere's Disease. J. Clin. Diagn. Res. JCDR 2016, 10, MC01-MC03. [CrossRef]

61. Davis, P.J.; Goglia, F.; Leonard, J.L. Nongenomic Actions of Thyroid Hormone. Nat. Rev. Endocrinol. 2016, 12, 111-121. [CrossRef]

62. Bergh, J.J.; Lin, H.-Y.; Lansing, L.; Mohamed, S.N.; Davis, F.B.; Mousa, S.; Davis, P.J. Integrin AV $\beta 3$ Contains a Cell Surface Receptor Site for Thyroid Hormone That Is Linked to Activation of Mitogen-Activated Protein Kinase and Induction of Angiogenesis. Endocrinology 2005, 146, 2864-2871. [CrossRef]

63. Darlington, C.L.; Smith, P.F. Molecular Mechanisms of Recovery from Vestibular Damage in Mammals: Recent Advances. Prog. Neurobiol. 2000, 62, 313-325. [CrossRef]

64. Smith, P.F.; Curthoys, I.S. Mechanisms of Recovery Following Unilateral Labyrinthectomy: A Review. Brain Res. Rev. 1989, 14, 155-180. [CrossRef]

65. Curthoys, I.S.; Halmagyi, G.M. Vestibular Compensation: A Review of the Oculomotor, Neural, and Clinical Consequences of Unilateral Vestibular Loss. J. Vestib. Res. Equilib. Orientat. 1995, 5, 67-107. [CrossRef]

66. Ris, L.; de Waele, C.; Serafin, M.; Vidal, P.P.; Godaux, E. Neuronal Activity in the Ipsilateral Vestibular Nucleus Following Unilateral Labyrinthectomy in the Alert Guinea Pig. J. Neurophysiol. 1995, 74, 2087-2099. [CrossRef] [PubMed]

67. Elliott, K.H.; Welcker, J.; Gaston, A.J.; Hatch, S.A.; Palace, V.; Hare, J.F.; Speakman, J.R.; Anderson, W.G. Thyroid Hormones Correlate with Resting Metabolic Rate, Not Daily Energy Expenditure, in Two Charadriiform Seabirds. Biol. Open 2013, 2, 580-586. [CrossRef] [PubMed]

68. Kim, B. Thyroid Hormone as a Determinant of Energy Expenditure and the Basal Metabolic Rate. Thyroid Off. J. Am. Thyroid Assoc. 2008, 18, 141-144. [CrossRef] [PubMed]

69. Martin, J.V.; Williams, D.B.; Fitzgerald, R.M.; Im, H.K.; Vonvoigtlander, P.F. Thyroid Hormonal Modulation of the Binding and Activity of the GABAA Receptor Complex of Brain. Neuroscience 1996, 73, 705-713. [CrossRef]

70. Puia, G.; Losi, G. Thyroid Hormones Modulate GABAA Receptor-Mediated Currents in Hippocampal Neurons. Neuropharmacology 2011, 60, 1254-1261. [CrossRef]

71. Paterson, J.M.; Short, D.; Flatman, P.W.; Seckl, J.R.; Aitken, A.; Dutia, M.B. Changes in Protein Expression in the Rat Medial Vestibular Nuclei during Vestibular Compensation. J. Physiol. 2006, 575, 777-788. [CrossRef]

72. Blomstrand, C.; Hallén, O.; Hamberger, A.; Jarlstedt, J. Quantitative Cytochemical Aspects on the Mechanism of Central Compensation after Unilateral Vestibular Neurotomy. Acta Otolaryngol. 1966, 61, 113-120. [CrossRef]

73. Shulga, A.; Thomas-Crusells, J.; Sigl, T.; Blaesse, A.; Mestres, P.; Meyer, M.; Yan, Q.; Kaila, K.; Saarma, M.; Rivera, C.; et al Posttraumatic GABAA-Mediated $\left[\mathrm{Ca}^{2+}\right]_{\mathrm{i}}$ Increase Is Essential for the Induction of Brain-Derived Neurotrophic Factor-Dependent Survival of Mature Central Neurons. J. Neurosci. 2008, 28, 6996-7005. [CrossRef]

74. Boulenguez, P.; Liabeuf, S.; Bos, R.; Bras, H.; Jean-Xavier, C.; Brocard, C.; Stil, A.; Darbon, P.; Cattaert, D.; Delpire, E.; et al. Down-Regulation of the Potassium-Chloride Cotransporter KCC2 Contributes to Spasticity after Spinal Cord Injury. Nat. Med. 2010, 16, 302-307. [CrossRef] [PubMed] 
75. Rivera, C.; Voipio, J.; Thomas-Crusells, J.; Li, H.; Emri, Z.; Sipilä, S.; Payne, J.A.; Minichiello, L.; Saarma, M.; Kaila, K. Mechanism of Activity-Dependent Downregulation of the Neuron-Specific K-Cl Cotransporter KCC2. J. Neurosci. 2004, 24, 4683-4691. [CrossRef] [PubMed]

76. Shulga, A.; Rivera, C. Interplay between Thyroxin, BDNF and GABA in Injured Neurons. Neuroscience 2013, $239,241-252$. [CrossRef]

77. Nygård, M.; Wahlström, G.M.; Gustafsson, M.V.; Tokumoto, Y.M.; Bondesson, M. Hormone-Dependent Repression of the E2F-1 Gene by Thyroid Hormone Receptors. Mol. Endocrinol. 2003, 17, 79-92. [CrossRef] [PubMed]

78. Capen, C.C. Mechanistic Data and Risk Assessment of Selected Toxic End Points of the Thyroid Gland. Toxicol. Pathol. 1997, 25, 39-48. [CrossRef] [PubMed]

79. Marouane, E.; El Mahmoudi, N.; Rastoldo, G.; Péricat, D.; Watabe, I.; Lapôtre, A.; Tonetto, A.; Xavier, F.; Dumas, O.; Chabbert, C.; et al. Sensorimotor Rehabilitation Promotes Vestibular Compensation in a Rodent Model of Acute Peripheral Vestibulopathy by Promoting Microgliogenesis in the Deafferented Vestibular Nuclei. Cells 2021, 10, 3377. [CrossRef] [PubMed]

80. Lima, F.R.; Gervais, A.; Colin, C.; Izembart, M.; Neto, V.M.; Mallat, M. Regulation of Microglial Development: A Novel Role for Thyroid Hormone. J. Neurosci. Off. J. Soc. Neurosci. 2001, 21, 2028-2038. [CrossRef]

81. Grosch, M.; Lindner, M.; Bartenstein, P.; Brandt, T.; Dieterich, M.; Ziegler, S.; Zwergal, A. Dynamic Whole-Brain Metabolic Connectivity during Vestibular Compensation in the Rat. NeuroImage 2020, 226, 117588. [CrossRef]

82. Zwergal, A.; Schlichtiger, J.; Xiong, G.; Beck, R.; Günther, L.; Schniepp, R.; Schöberl, F.; Jahn, K.; Brandt, T.; Strupp, M.; et al Sequential $\left[{ }^{18}\right.$ F]FDG MPET Whole-Brain Imaging of Central Vestibular Compensation: A Model of Deafferentation-Induced Brain Plasticity. Brain Struct. Funct. 2016, 221, 159-170. [CrossRef]

83. Bloise, F.F.; Cordeiro, A.; Ortiga-Carvalho, T.M. Role of Thyroid Hormone in Skeletal Muscle Physiology. J. Endocrinol. 2018, 236, R57-R68. [CrossRef] [PubMed]

84. Simonides, W.S.; van Hardeveld, C. Thyroid Hormone as a Determinant of Metabolic and Contractile Phenotype of Skeletal Muscle. Thyroid Off. J. Am. Thyroid Assoc. 2008, 18, 205-216. [CrossRef] [PubMed]

85. Zennou-Azogui, Y.; Borel, L.; Lacour, M.; Ez-Zaher, L.; Ouaknine, M. Recovery of Head Postural Control Following Unilateral Vestibular Neurectomy in the Cat: Neck Muscle Activity and Neuronal Correlates in Deiters' Nuclei. Acta Otolaryngol. 1993, 113, 5-19. [CrossRef]

86. Simon, F.; Pericat, D.; Djian, C.; Fricker, D.; Denoyelle, F.; Beraneck, M. Surgical Techniques and Functional Evaluation for Vestibular Lesions in the Mouse: Unilateral Labyrinthectomy (UL) and Unilateral Vestibular Neurectomy (UVN). J. Neurol. 2020, 267, 51-61. [CrossRef] [PubMed]

87. Teufert, K.B.; Doherty, J. Endolymphatic Sac Shunt, Labyrinthectomy, and Vestibular Nerve Section in Meniere's Disease. Otolaryngol. Clin. N. Am. 2010, 43, 1091-1111. [CrossRef]

88. Magnan, J.; Bremond, G.; Chays, A.; Gignac, D.; Florence, A. Vestibular Neurotomy by Retrosigmoid Approach: Technique, Indications, and Results. Am. J. Otol. 1991, 12, 101-104.

89. Vignaux, G.; Chabbert, C.; Gaboyard-Niay, S.; Travo, C.; Machado, M.L.; Denise, P.; Comoz, F.; Hitier, M.; Landemore, G.; Philoxène, B.; et al. Evaluation of the Chemical Model of Vestibular Lesions Induced by Arsanilate in Rats. Toxicol. Appl. Pharmacol. 2012, 258, 61-71. [CrossRef]

90. Callejo, A.; Sedó-Cabezón, L.; Juan, I.D.; Llorens, J. Cisplatin-Induced Ototoxicity: Effects, Mechanisms and Protection Strategies. Toxics 2015, 3, 268-293. [CrossRef]

91. Cassel, R.; Bordiga, P.; Carcaud, J.; Simon, F.; Beraneck, M.; Le Gall, A.; Benoit, A.; Bouet, V.; Philoxene, B.; Besnard, S.; et al. Morphological and Functional Correlates of Vestibular Synaptic Deafferentation and Repair in a Mouse Model of Acute-Onset Vertigo. Dis. Model. Mech. 2019, 12, dmm039115. [CrossRef] 